Review

\title{
Challenges Facing the Implementation of Pico-Hydropower Technologies
}

Samuel J. Williamson ${ }^{1, *}$, W. David Lubitz ${ }^{2}$, Arthur A. Williams ${ }^{3}$, Julian D. Booker ${ }^{1}$, Joseph P. Butchers ${ }^{1}$

1 Faculty of Engineering, University of Bristol, University Walk, Bristol, BS8 1TR, UK

2 School of Engineering, University of Guelph, 50 Stone. Rd. E., Guelph, ON, N1G 2W1, Canada

3 Department of Electrical and Electronic Engineering, University of Nottingham, University Park, Nottingham, NG7 2RD, UK

* Correspondence: Samuel J. Williamson, Email: sam.williamson@bristol.ac.uk; Tel.: +44-117-954-5177.

\section{ABSTRACT}

840 million people living in rural areas across the world lack access to electricity, creating a large imbalance in the development potential between urban and rural areas. Pico-hydropower offers a cost-effective way of accessing electricity, where the resource exists. This paper discusses and critically examines several challenges that remain in implementing pico-hydropower systems, such as local manufacturing, maintenance and repair of turbines, low-head solutions, dealing with variation in the water flow between seasons, the ability to deal with income generating loads and low system power and capacity factor. The solutions to many of these problems exist; several low head turbine systems are appearing on the market, and new power electronic packages are able to improve the system capacity factor. Some turbines are now being designed for local construction using design for manufacturing rules, so only basic workshop tools and process are required to build turbine systems and components, and enabling turbines to be locally repaired. Through the commercialisation and implementation of these solutions, the proliferation of pico-hydropower systems can take place providing low cost sustainable electricity for remote communities, but this requires a stronger emphasis in social awareness and policy. Three critical enabling factors for the success of pico-hydropower projects are identified through this analysis: understanding the local context, financial sustainability and stakeholder awareness.

KEYWORDS: pico-hydropower; low head; local manufacturing; energy access
Received: 04 October 2019

Accepted: 03 December 2019

Published: 04 December 2019

Copyright (c) 2019 by the author(s). Licensee Hapres, London, United Kingdom. This is an open access article distributed under the terms and conditions of Creative Commons Attribution 4.0 International License. 


\section{INTRODUCTION}

Energy access is crucial to development and raising people out of poverty, and plays such a critical part that it has been recognised by the UN in their Sustainable Development Goals (SDG), with Goal 7 stating "Ensure access to affordable, reliable, sustainable and modern energy for all” [1]. Along with this specific goal, energy has positive, enabling relationships with nearly all of the other SDGs [2,3], supporting the achievement of these goals. For example, cleaner and more efficient cooking fuels are able to reduce the time that women and children spend in dangerous areas carrying out drudgery tasks, reducing the potential for gender-based violence. Similarly, educational potential increases with electricity access, with students able to study in well light, thermally comfortable classrooms, with access to modern information and communication. The UN has seen energy access as such a priority that it declared 2014-2024 as the Decade of Sustainable Energy for All [4]. The aims of the program are by 2030 to provide universal energy access, double the improvement in energy efficiency and double the global share of renewable energy, which align with the targets of SDG 7.

As of 2019, 840 million people living in rural areas have no access to electricity [5]. Of these, half are in Sub-Saharan Africa, as shown in Figure 1 [6], where many countries have rural electrification rates of $10 \%$ or less.

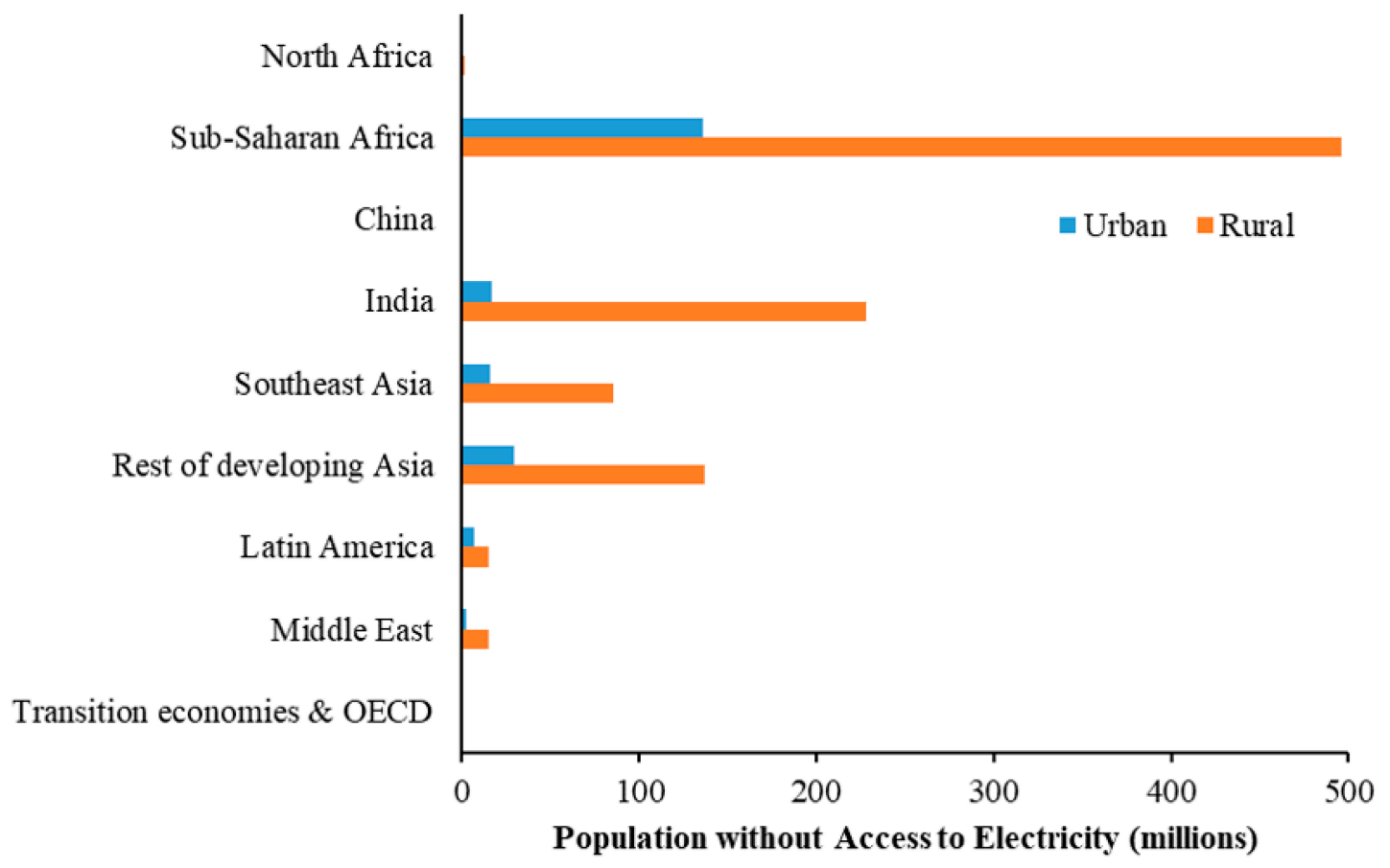

Figure 1. Urban and rural populations without electricity [6].

There are three main types of barrier to electricity access: economic, geographic and political [7]. Extending a national grid within an urbanised environment is a relatively low cost proposition, and 
geographic barriers are irrelevant as houses are located close to one another, but there must be a political consensus to expand the grid. However, all three of these barrier types are often present in the case of rural electrification, with low population density leading to an increased cost per connection, natural geographical barriers such as mountains, valleys and rivers, and a lack of political will to supply electricity or political interference with electrification programmes [8]. Therefore, remote and rural communities become reliant on local, off-grid generation for their electricity supply.

Diesel generators are a standard choice for off-grid communities, utilising well-known technology with a low capital cost. However, without regular servicing and maintenance, diesel generators are prone to failure in rural environments [9]. They depend on good fuel supply infrastructure, are at the mercy of large fluctuations in oil price, and produce greenhouse gas and carbon dioxide emissions during operation. Therefore, renewable technologies-solar photovoltaics, wind, hydropower and biomass-are attractive for off-grid communities, providing locally generated electricity from local resources. More recently, locally produced oils have also been tested to use in converted diesel generator sets [10], which remove the dependency on fuel supply and price volatility.

The selection of the appropriate renewable energy generator for a community is dependent on the resources available at the site. An important early step in the design of a community power supply is to assess all local resources. The resource selection also places requirements on the design of the system, with solar and wind generators requiring electrical storage to manage inherent short-term resource variability. Biomass and hydropower resource can be considered to be more constant, with variations only occurring in the longer term with changing seasons.

Hydropower is a well-known and extensively used renewable energy source. It has many positive attributes, such as providing a generally reliable and consistent supply, but also challenges associated with its implementation, such as the environmental impact of large-scale systems. At a community scale, small "pico" versions of the turbines systems can be used to provide power. However, there are many technical, social, economic and policy challenges facing the implementation of pico-hydropower systems, especially when they are competing with technologies such as solar photovoltaic systems. In this paper, four interdisciplinary challenges are highlighted and discussed in depth: the adoption of low head turbine solutions, variable water flow rate, low power generation and capacity factor, and local manufacturing of turbine systems. Research has demonstrated new and current solutions are available to overcome these issues. These ideas and concepts are presented and reviewed in this paper along with the potential 
opportunities generated arising from the challenges, and non-technical enablers required to support future success in this field.

\section{BACKGROUND}

Pico-hydropower is generally defined as an electrical generation system with a capacity to provide up to $5 \mathrm{~kW}$ of electricity from a water flow [11]. There are many different turbines that can be used in a number of different environmental conditions, as shown in Table 1, with the most common solutions highlighted. For this work, we have not included hydrokinetic (zero-head) systems as they use a different method in generating mechanical power from the kinetic energy in the stream flow rather than pressure head from gravitational potential, and require significantly different civil structures to implement the solutions. These application ranges are not fixed, and most turbines are able to be used across all the head ranges, although physical limitations may apply, such as cavitation, which occurs when operating a reaction turbine at high heads, or turbine size, when using impulse turbines at low heads, the physical size becomes extremely large do to the volume of water consumed [12]. Pico-hydro systems are normally stand-alone, with no other power source on the network, and are installed as run-of-river systems, so do not have a large amount of water storage, which minimises the environmental impact.

Table 1. Hydropower turbines and their operating heads (developed from [13]), with common pico-hydropower solutions highlighted in bold italic text.

\begin{tabular}{cccc}
\hline Turbine Type & \multicolumn{3}{c}{ Head Range } \\
\cline { 2 - 4 } & $\begin{array}{c}\text { Low Head } \\
(<\mathbf{1 0} \mathbf{~ m})\end{array}$ & $\begin{array}{c}\text { Medium Head } \\
(\mathbf{1 0}-\mathbf{5 0} \mathbf{m})\end{array}$ & $\begin{array}{c}\text { High Head } \\
(>\mathbf{5 0 ~ m )}\end{array}$ \\
\hline \multirow{2}{*}{ Impulse } & Crossflow & $\begin{array}{c}\text { Multi-jet Pelton/Turgo, } \\
\text { Crossflow }\end{array}$ & $\begin{array}{c}\text { Single-jet Pelton/Turgo } \\
\text { Multi-jet Pelton }\end{array}$ \\
\hline \multirow{2}{*}{ Reaction } & $\begin{array}{c}\text { Radial flow (Francis) } \\
\text { Axial flow (Kaplan) }\end{array}$ & Radial flow (Francis) & \\
\hline Waterwheel & $\begin{array}{c}\text { Overshot } \\
\text { Breastshot } \\
\text { Undershot }\end{array}$ & & \\
\hline
\end{tabular}

\section{Archimedes screw}

\section{Pump-as-Turbine}

Other Hydrostatic pressure machine ${ }^{1}$ Split-pipe ${ }^{2}$

Pump-as-Turbine

Cross-pipe ${ }^{2}$
Cross-pipe ${ }^{2}$

Gravitational vortex turbine

1 The Stem pressure machine is analysed in [14].

2 The split-pipe and cross-pipe turbines are described in detail in [15].

A typical layout of a pico-hydropower system is shown in Figure 2. The water from the river is diverted into an intake canal through a dam or weir (1), which keeps the flow to the turbine constant during high and low flow periods. The water passes through an intake canal (2), leading to 
the forebay tank (3), which provides some water storage and has the inlet to the penstock built into it. The penstock is the pipe leading from the tank to the turbine (4). A trash rack is used to remove any larger pieces of debris from the water before it enters the penstock. A forebay tank is not always required, if the penstock can be located in a natural pool in the feeding river or stream. A penstock may not be required for some low head sites, as the turbine design may not require it. The water reaches the powerhouse (5), where the turbine, generator and electrical equipment are located, then exits the powerhouse through the tailrace and is returned to the river. The turbine is often connected to the generator by a belt drive system, to match the rotational speed of the turbine and generator. The power from the generator is then dispatched through power lines to the transmission area (6), where it is connected to the consumers.

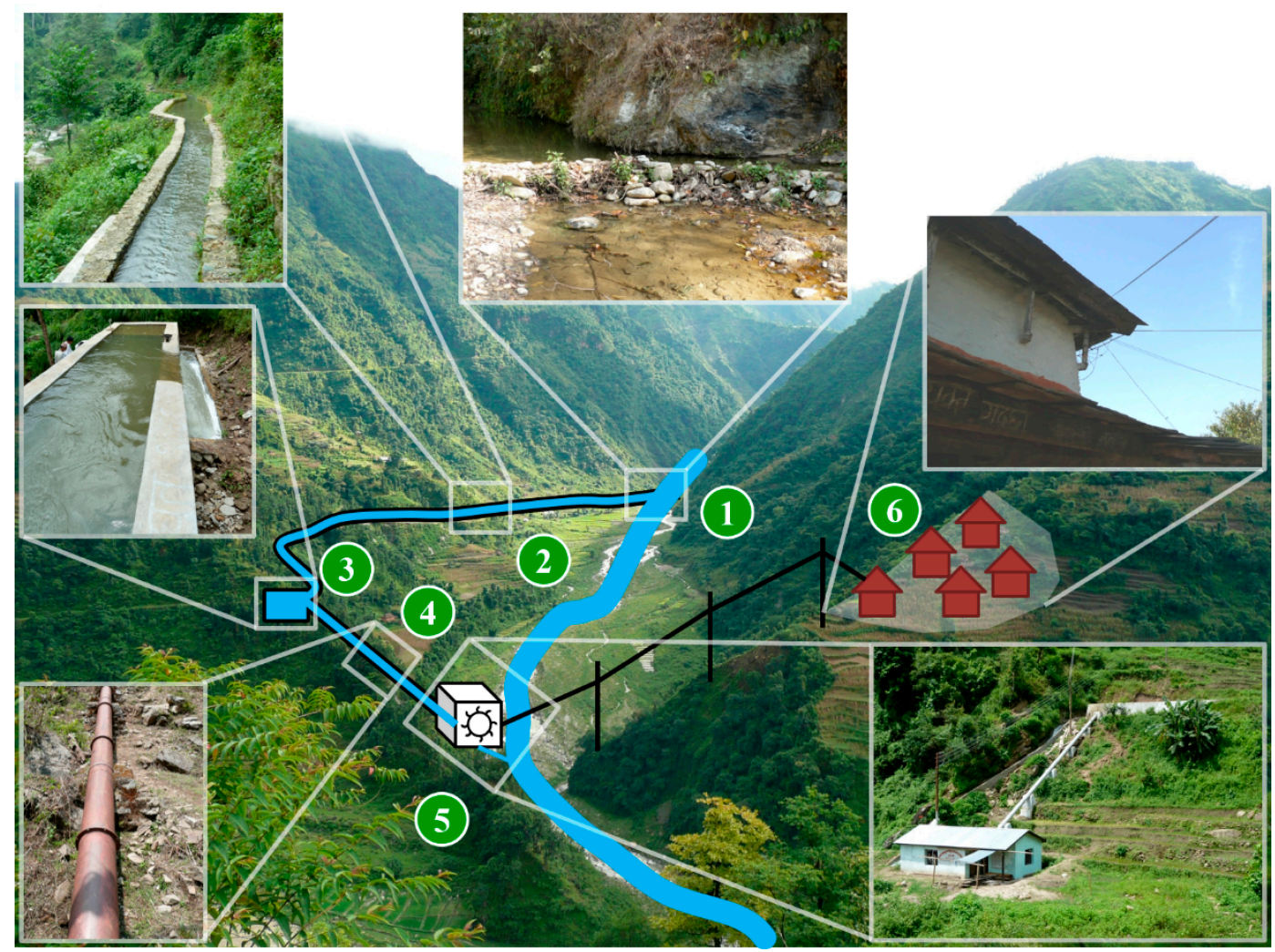

Figure 2. Typical pico-hydropower installation layout: (1). Dam/weir site, (2). Intake canal, (3). Forebay tank, (4). Penstock, (5). Powerhouse, (6). Distribution area [16].

Many rural communities have perennial flowing water sources nearby that are utilised for drinking water and crop irrigation. Pico-hydropower is a realistic option to provide electrical power to these communities without access to electricity. However, there are several challenges facing the proliferation of pico-hydropower in the Global South, as discussed below.

- Adoption of low head pico-hydropower turbine solutions: At medium to high head, above $25 \mathrm{~m}$, there are a number of easily 
accessible turbine system options to install making it readily available for small-scale developers. The most popular is the Pelton turbine, which has proved to be reliable, with off-the-shelf turbines available as well as locally built designs such as the Pico Power Pack [17]. These designs can be easily modified and tuned for varying environmental conditions and seasonal flows. Medium head Crossflow turbines have also been extensively used and the design can be easily modified to allow for different environmental conditions. However, for low-head situations, there is no standard simple scheme, as reaction turbines are complex to design and manufacture, and require a regular, constant flow and head all year around to operate. Therefore, the adoption of low-head technologies is much less than that of its higher head counterparts.

- Variable flow/head solutions for pico-hydropower systems: In the design of pico-hydropower systems, it is assumed that the water flow rate remains constant during the year, but there are often seasonal changes. For example, the South Asian monsoon provides a large influx of water from June to September, but from December to March many rivers in the region flow with $10 \%$ of the peak flow rate [18]. A turbine is ideally designed for the minimum flow, but during large portions of the year in many locations, this would be only a small fraction of available energy, with a large amount of the potential energy going to waste.

- Low power and capacity factor: The electrical generation by pico-hydropower is by its nature small. The power available is often less than $1 \mathrm{~kW}$, and so unable to supply motor loads. Therefore, most of the loads supplied by pico-hydropower schemes are domestic, consisting of lighting, powering radios, and charging mobile phones, tablets and laptop computers. Without the use of income generation loads, the full benefit of the electrical supply is not realised and many schemes are not economically viable. Also, domestic loads are normally only used during two peaks in the day; in the morning as the community wakes up, and in the evening as they prepare for the evening meal and go to bed. At these times, there is excess demand on the system, causing voltage sag or often causing the circuit breaker to trip. Outside these peak times, excess electrical power generated is dumped into air heaters, and the useful capacity factor of the plant is reduced.

- Local manufacturing of pico-hydropower systems in developing countries: There are two options for manufacturing pico-hydropower systems, either they are available as an off-the-shelf unit or they are manufactured locally. Off-the-shelf units allow for cost savings due to economies of scale in the manufacturing process, but do not provide opportunities for local businesses to develop technical skills to construct, maintain and develop the turbines outside their stated operating ranges. Locally built turbine systems allow local workshops 
to make customised turbine designs for unique environmental conditions, provide local skilled jobs for the community, and enable local repair at low cost. However, a quality control guarantee for these turbine solutions can be difficult to implement leading to either poor performance or premature failure, and the techniques for manufacturing the more complex components in the system may not be available in local workshops.

These challenges and potential solutions to these challenges are discussed individually in the following sections.

\section{LOW-HEAD PICO-HYDROPOWER TURBINE SOLUTIONS}

Only a few metres of head is required to operate some turbine designs, and low-head turbine sites are prevalent all over the world [19]. Many installations of locally built mills already exist. For example, locally built mills in South Asia, known as Ghatta or Gharat, have operated with low head for many years. There are several off-the-shelf solutions for low-head turbines. These are typically open flume axial flow turbines, with examples including the PowerPal LH series [20], the PowerSpout LH [21], and the Energy Systems and Design LH1000 [22]. These units are all of similar design, manufactured to a good quality and available worldwide. There are also poorly manufactured versions of these turbines, which are sold for a very low cost in China, Vietnam and Laos [23]. These systems are often called "family hydro" [24], due to their use by a single family, and can be locally modified to adapt to the river conditions [25], as shown in Figure 3.

(A)

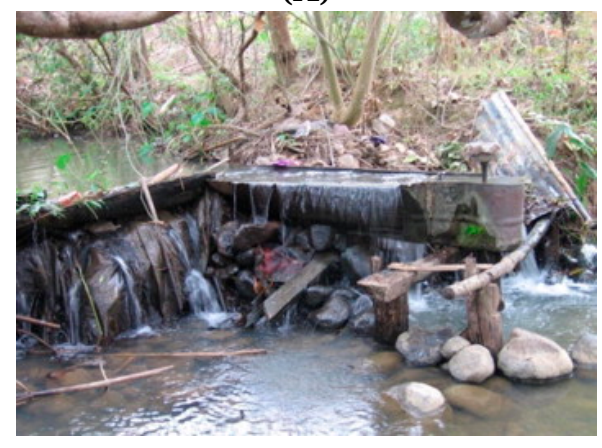

(B)

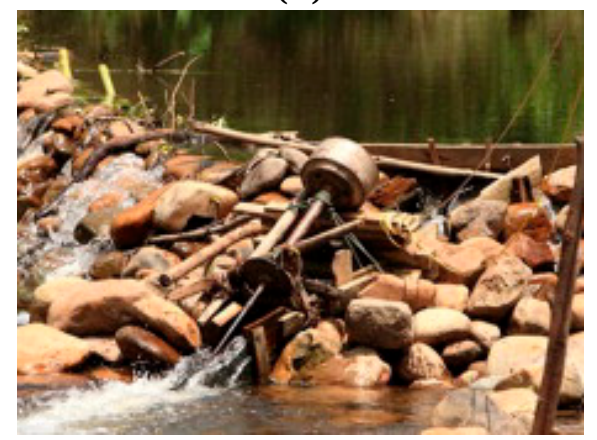

(C)

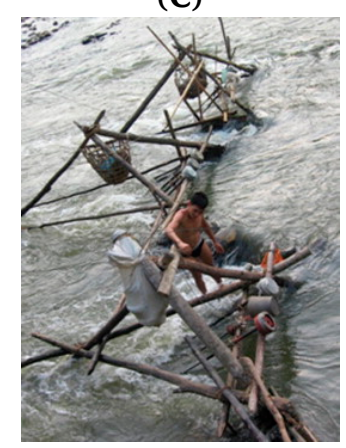

Figure 3. "Family hydro" adaptations for (A) standing, (B) angled and (C) lying situations. Reproduced with permission from [25], @ 2012 Elsevier Ltd.).

Family hydro systems are normally expected to last between 12 and 36 months before failing [23-25], requiring a change of bearings, generator or a new turbine to be purchased. One major design issue with the open flume turbine is that the bearing under the turbine must be constantly submerged. Therefore, unless the seal between the shaft and bearing housing is very good quality, the bearing is likely to fail prematurely due to the ingress of water and silt, contaminating the lubricant. 
Crossflow turbines have been used extensively at medium to low heads. Once the head falls below five metres, many companies will not install a Crossflow turbine. However, the Ossberger version of the Crossflow turbine [26], shown in Figure 4, can operate down to heads of 2.5 metres, using a draft tube to raise the turbine above the flood level, and allowing the turbine to use the full amount of head available to it. The Crossflow turbine has been shown to be extremely robust, an insensitivity to variations in operating circumstances, environmental effects and service conditions, due to the simplicity of design and operational modes [27].

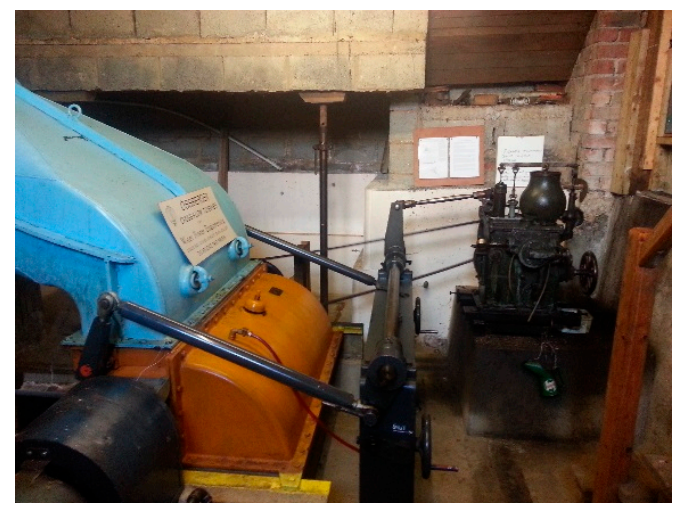

Figure 4. Ossberger Crossflow turbine with draft tube installation in UK (Photo credit: Sam Williamson).

The concept of the Archimedes screw as a turbine has been developed in the last 25 years [28-30], although historically these screws have been used for thousands of years to lift water [31]. Hundreds of these turbines have been installed across Europe, primarily at existing dams, weirs and small falls [32]. They are popular with river authorities due to their perceived "fish friendliness" [33] and are also extremely robust due to its simple design and operating principles [28]. (Note: in other turbines, a well-designed intake and fish bypass or ladder will ensure fish do not pass through the turbine, so the advantage here is due to the removal of head reduction by a fine intake and cost-reducing system simplicity.)

Archimedes screws are best suited to very low heads of less than about 5 meters. The standard inclination angle for a screw is $20^{\circ}$ to $30^{\circ}$, meaning that the length of the screw is approximately double the head used. This can mean that the Archimedes screw is often physically large relative to its power output, and so this puts an upper limit on the feasible size. For these reasons it is often not an ideal pico-hydropower turbine choice for rural, remote communities, except in very low head locations. However, since Archimedes screws can be operated efficiently even at near zero heads [34], pico-scale Archimedes screws can be feasibly deployed at locations with head in the range of $0.5 \mathrm{~m}$ to $1.5 \mathrm{~m}$, and it is at these extremely low heads where they are advantageous.

Rohmer et al. [35] tested a prototype pico-scale Archimedes screw generator that produced up to $1.6 \mathrm{~kW}$ shaft power with a flow of $170 \mathrm{~L} / \mathrm{s}$. They observed mechanical efficiencies as high as $82 \%$, with major losses 
due to leakage flow and fluid friction within the screw. A $400 \mathrm{~W}$ prototype tested in Canada [36], shown in Figure 5, had a water-to-wire efficiency of about $65 \%$, which is comparable to an average $69 \%$ water-to-wire efficiency for larger-grid-connected Archimedes screw plants.

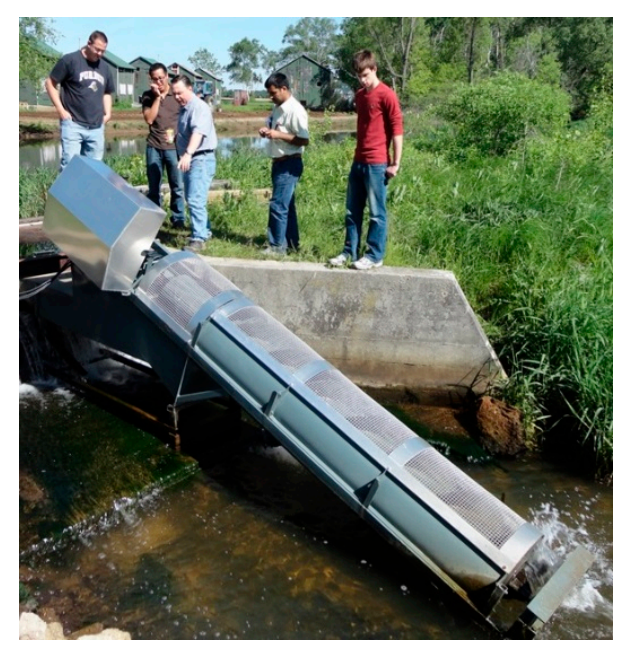

Figure 5. A $400 \mathrm{~W}$ pico-hydropower scale Archimedes screw prototype ( $0.9 \mathrm{~m} \mathrm{head,} 70 \mathrm{~L} / \mathrm{s}$ design flow) in Canada (Photo credit: Greenbug Energy Inc.).

In Nepal, a locally designed and developed low-head pico-hydro propeller (axial) turbine has been undergoing research lab tests, whilst a number of examples have been installed at sites across the country [37]. The PT series turbine, originally developed by Nepal Hydro and Electric and the United Mission to Nepal, has gone through two iterations. Initially an open flume design was used, similar to those in Figure 3. Later installations used a closed flume design with a volute casing, as shown in Figure 6A. This second design removed the need for a submerged bearing, increasing the reliability of the system. The complete system water-to-wire efficiency, using an induction machine as a generator, was measured to be $54 \%$, with the turbine efficiency estimated to be around $77 \%$, the other losses coming from the control system and generator. The results from the turbine testing at Kathmandu University are shown in Figure 6B. A family of the PT turbines has been developed, ranging from $0.3 \mathrm{~kW}$ to $3 \mathrm{~kW}$, using non-dimensional scaling, and able to be matched with standard induction generators, which reduces the cost of implementation. 
(A)

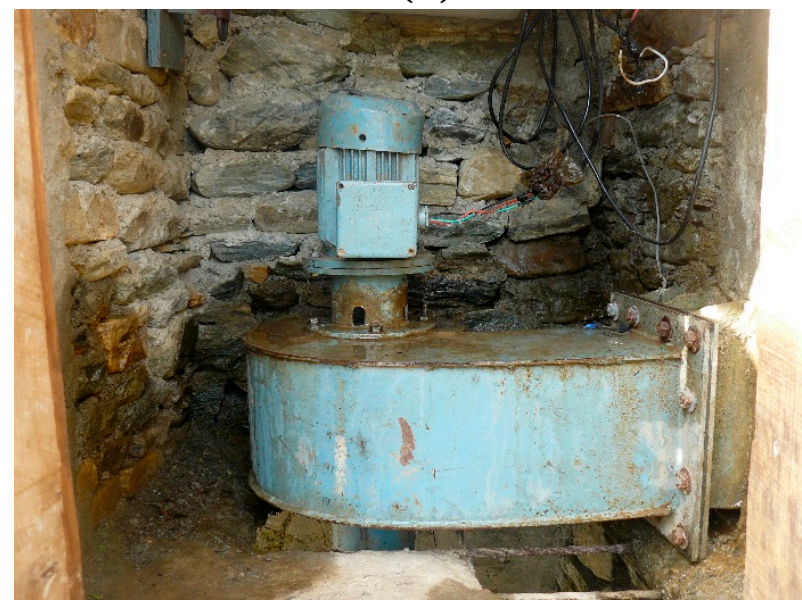

(B)

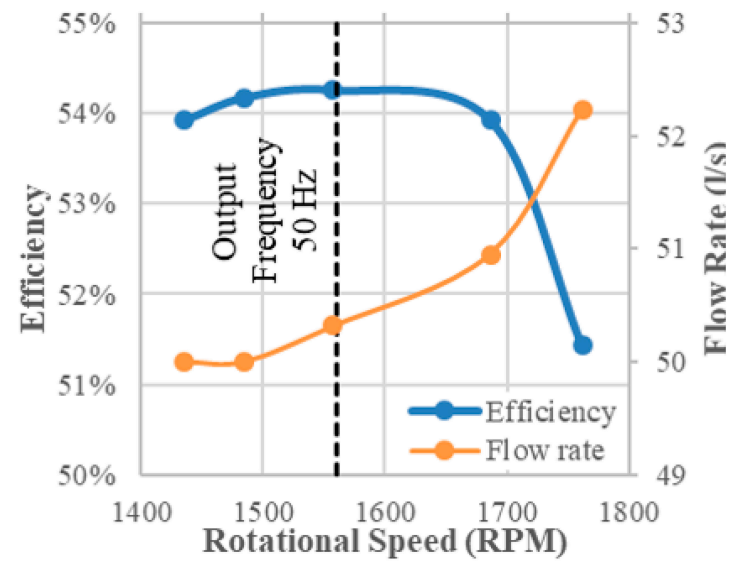

Figure 6. (A) Photo of PT03 turbine implemented in Nepal (Photo credit: Sam Williamson). (B) Power curve for PT1 turbine measured at Kathmandu University’s Turbine Testing Laboratory [38].

Research from the University of Bristol [12,39] has proposed using a Turgo turbine at low head, as shown in Figure 7A. The same unit can be applied at a variety of sites with different head and flow regimes without having to change the design of the system. The turbine also has the potential for very high efficiencies, scale laboratory tests showed measured jet-to-mechanical efficiency of the turbine to be $90 \%$ at $3.5 \mathrm{~m}$ head, as shown in Figure 7B. Assuming a generator efficiency of $90 \%$ for a permanent magnet generator, then the water-to-wire efficiency would be $81 \%$. The design is able to be easily integrated into existing water infrastructure [40], reducing cost at installation and minimising environmental impact. This turbine has yet to be tested in the field, however.

(A)

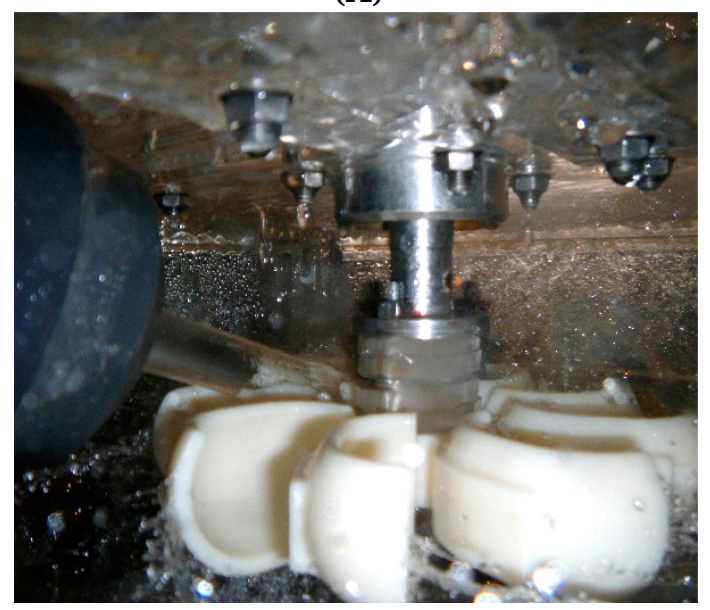

(B)

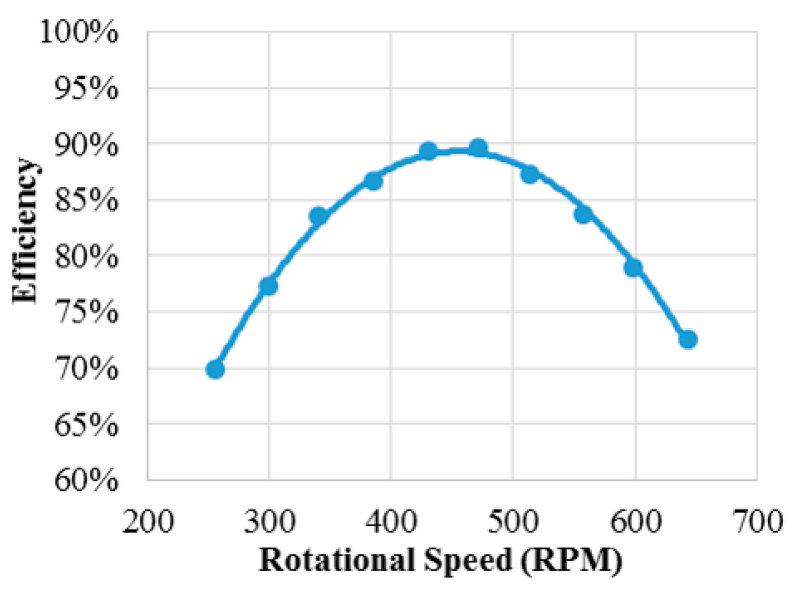

Figure 7. (A) Low-head Turgo turbine, proposed by [12,39] (Photo credit: Sam Williamson). (B) Jet-to-mechanical efficiency curve for low-head Turgo turbine, measured in scale laboratory testing [39]. 
The Gravitational Water Vortex Power Plant [41] has been proposed as an efficient, multi-use turbine system, with the ability to generate power, aerate the water and allow fish migration paths without the need for fish ladders. The turbine basin generates a vortex, exiting at the base of the basin, as shown in Figure 8. A turbine is placed in the centre of the vortex, using the rotational water field to generate torque on the runner. It has been implemented in sites in Austria [40], Indonesia, Nepal [42,43] and Peru [44], as well as being studied for its application in waste water plants in Ireland [45]. This turbine does not require any complicated manufacturing processes, with only metal rolling and welding required. However, there is some scepticism in its use [46], with low efficiencies found in some laboratory experiments $[42,44,45]$, whilst some authors claim higher efficiencies, close to $75 \%$, at $1.5 \mathrm{~m}$ head and water flow rate of $0.2 \mathrm{~m}^{3} / \mathrm{s}$ [43].

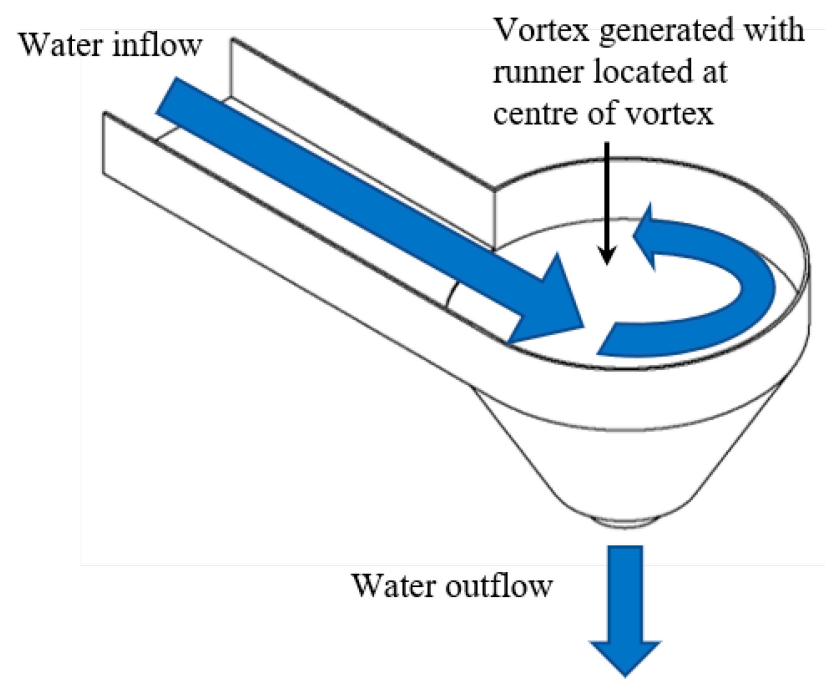

Figure 8. Gravitational Vortex Water Power Plant basin, generating a vortex from water inflow.

Some of these turbine designs and innovations have been commercially realised, whilst others are still in the research and development stage. All designs provide the opportunity to develop useful amounts of power at low heads. To support the proliferation of these turbines, alongside further technological development where required, programmes to promote and raise awareness amongst potential suppliers, installers and customers must take place. Policy must be established to enable and encourage new and emerging technological solutions, with access to subsidies and required approvals. These mechanisms will enable a wider low head pico-hydropower market to develop with appropriate technologies.

\section{VARIABLE FLOW/HEAD SOLUTIONS FOR PICO-HYDROPOWER SYSTEMS}

The civil works for hydropower schemes are used to maintain as constant as possible environmental conditions at the turbine intakes. The 
turbine design point is often for minimum flow and head conditions. However, the flow rate varies across the seasons, and often is much larger than the minimum conditions, as shown by the example flow duration curves in Figure 9 from the UK and Nepal. This degree of seasonal variation in flow is common in the smaller, unregulated watercourses typically used for pico-hydropower systems, across a wide range of climates and landscapes. This means that if a fixed capacity system is sized for the minimum flow in order to provide reliable all year-round power, as shown in Figure 9, a large amount of the available power in the watercourse could not be utilised for much of the year.

(A)

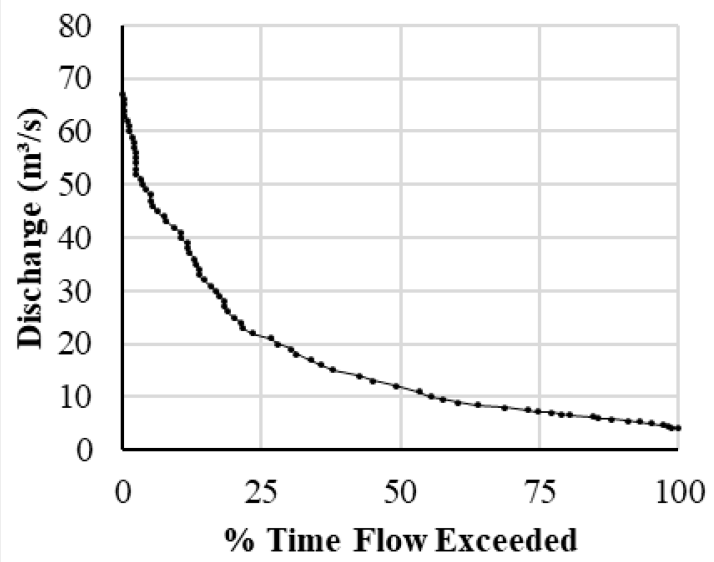

(B)

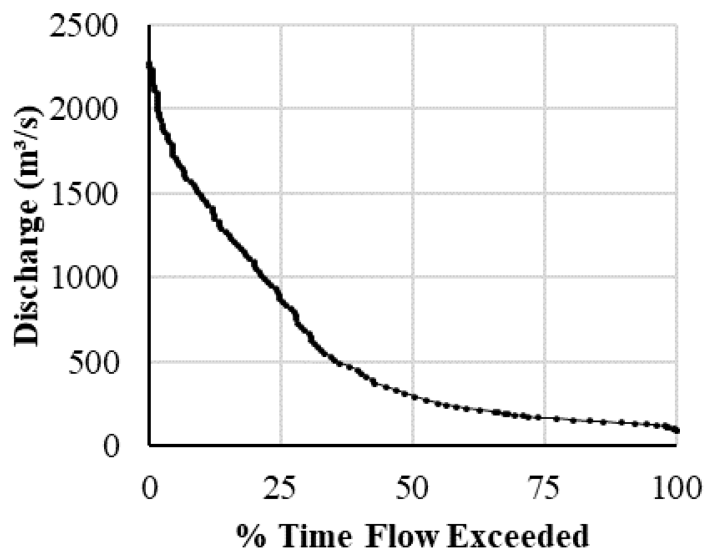

Figure 9. Flow duration curves for (A) rainfall- and groundwater-fed river in the UK and (B) a glacier-fed river in Nepal. (Data taken from [47] and [18]).

Some turbine designs can be modified to allow a variable flow rate into the turbine. Pelton and Turgo turbines normally use a spear valve to dynamically control the flow to the turbine and allow the turbine to operate efficiently across a wide range of flow rates, Figure 10. However, for pico-hydropower scale turbines, variable geometry nozzles can be expensive, and when used they are often manually actuated. In this case, a reduced inflow rate with a fixed nozzle size causes the penstock to run part full. This decreases the effective head to the turbine, reducing the speed of the jet. To maintain the efficiency of the fluid power torque generating mechanism the rotational speed must reduce with the flow. When using multiple nozzles, individual nozzles can be closed as the flow rate reduces, maintaining the head at the turbine and therefore the runner speed. As with Pelton and Turgo turbines, the inlet nozzle area of a Crossflow turbine can be varied using a deflection plate or nozzle, or through a distributor vane creating a variable opening at the wheel entrance. They also have the possibility of separating the turbine into segments, and only running the flow through part of the turbine [26], therefore reducing the required flow rate and increasing the operating envelope. 


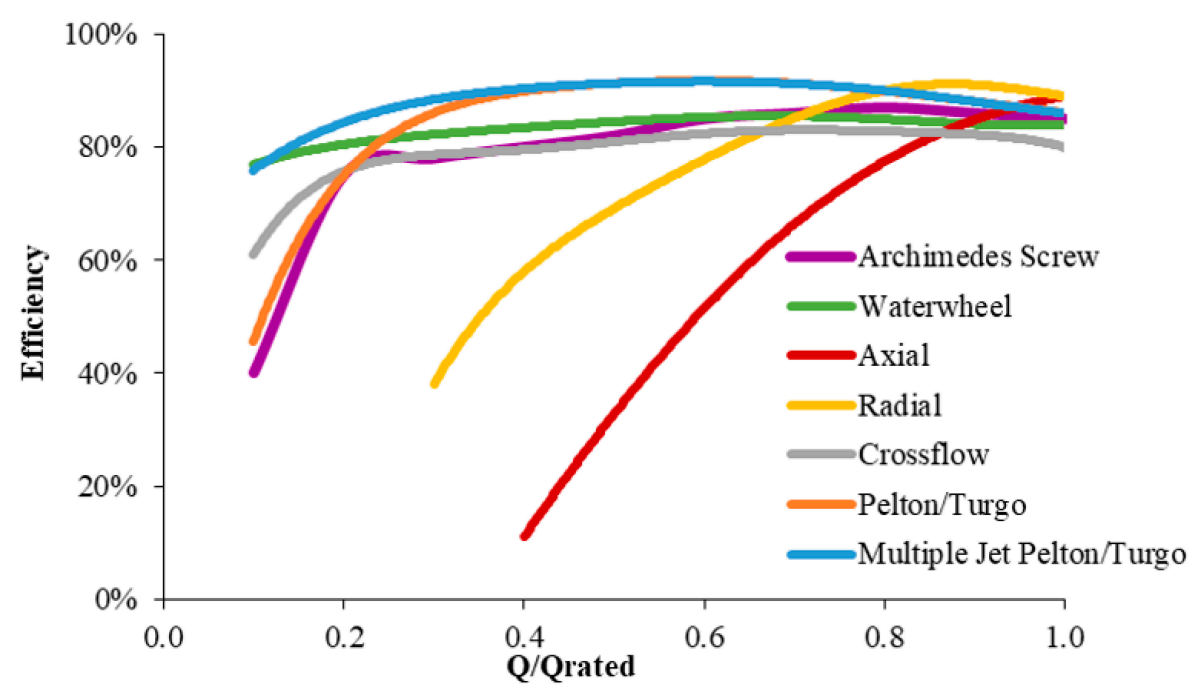

Figure 10. Turbine efficiency for variable flow rates with different turbine designs (compiled from $[13,33,48-51])$.

Figure 11 shows experimental tests that took place on a small Pelton turbine with different fixed nozzle sizes demonstrating that it is possible to achieve reasonable efficiency over a wide range of fixed flow rates. This analysis takes into account the change in head loss for different flow rates, and is based on a gross head of $25 \mathrm{~m}$. As flow rate increases, there is a marginal increase in optimum speed, which would fit well with increasing slip of an induction generator [52]. In Table 2, the performance for different nozzle diameters is shown. However, two details should be noted. Firstly, in order to maintain a good efficiency, it is necessary to move the nozzle to impact at a smaller radius on the Pelton runner. Secondly, with the largest nozzle, which is much greater than usually recommended, there is a rapid drop in output if the speed is allowed to increase. This is due to the large amount of water which rebounds and interferes with the rotation of the runner. Similar problems can occur if multiple jets are used with a small diameter Pelton.

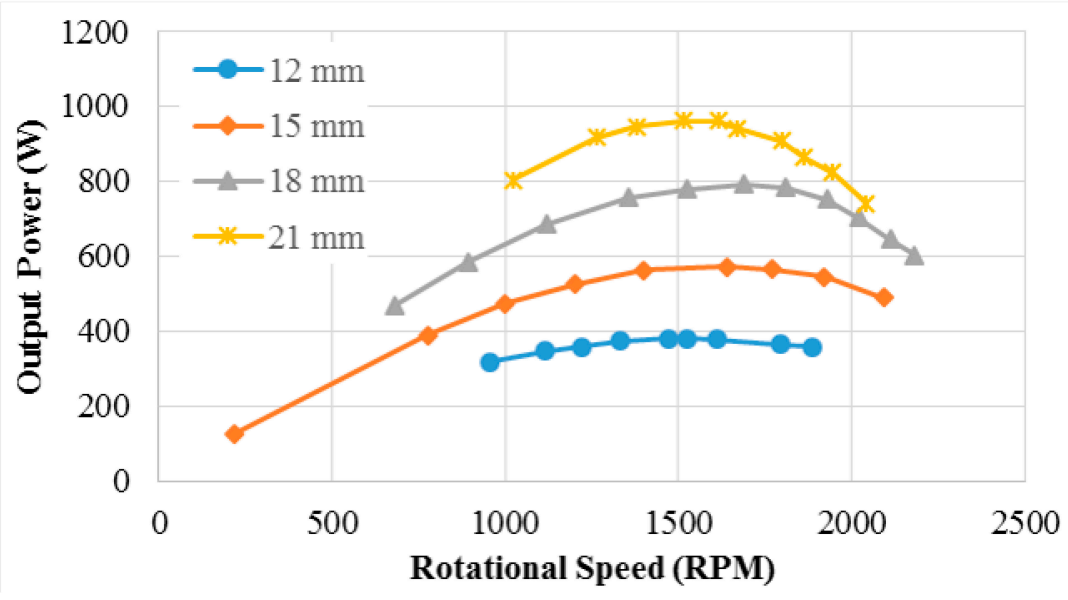

Figure 11. Experimental Tests on a nominal $120 \mathrm{~mm}$ pitch circle diameter Pelton turbine with different nozzle diameters [52]. 
Table 2. Performance of small Pelton turbine with different fixed nozzles [52].

\begin{tabular}{cccccc}
\hline $\begin{array}{c}\text { Nozzle dia. } \\
(\mathbf{m m})\end{array}$ & $\begin{array}{c}\text { Flow Rate } \\
\text { (L/s) }\end{array}$ & $\begin{array}{c}\text { Net Head } \\
(\mathbf{m})\end{array}$ & $\begin{array}{c}\text { Operating Speed } \\
\text { (rev/min) }\end{array}$ & $\begin{array}{c}\text { Nozzle position } \\
\text { (radius in } \mathbf{~ m m})\end{array}$ & $\begin{array}{c}\text { Efficiency } \\
\text { (\%) }\end{array}$ \\
\hline 12 & 2.13 & 24.7 & 1530 & 62 & 74 \\
\hline 15 & 3.41 & 24.3 & 1545 & 60 & 72 \\
\hline 18 & 4.68 & 23.6 & 1560 & 60 & 72 \\
\hline 21 & 6.28 & 22.5 & 1575 & 57 & 69 \\
\hline
\end{tabular}

The low-head Turgo turbine proposed in [39] has been shown to operate efficiently over a variable flow rate, Figure 12 . As the flow rate reduces, the head at the turbine reduces for a constant nozzle diameter, therefore a change in head represents a change in flow rate. This novel design for low heads offers the opportunity for a single turbine design to be used over multiple sites with different environmental conditions, which could operate efficiently during low- and high-flow periods and increase overall energy generation.

(A)

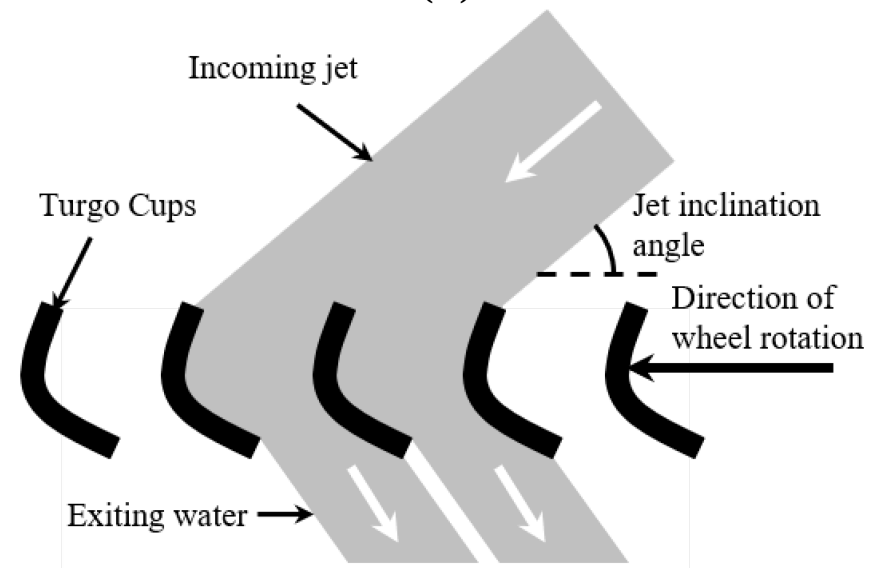

(B)

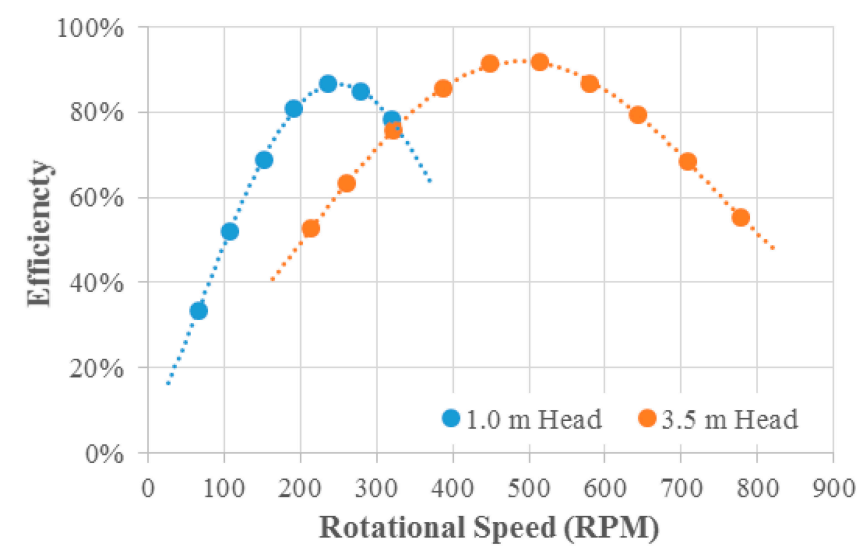

Figure 12. (A) Torque generation mechanism for Turgo turbine. (B) Low-head Turgo turbine tested at variable heads and flow rates [31].

The variable flow operation of waterwheels has shown them to be efficient over a wide range of flow rates [48,49,53-55]. Archimedes screw generators are capable of operating efficiently at very low flows [56], particularly if configured for variable speed control [57]. Low flow operation of Archimedes screws is generally limited by minimum generator torque requirements, rather than by the dynamics of the screw itself [58] and variable speed generators are increasingly common in grid-connected Archimedes screw to allow efficient operation at sites with large seasonal flow variation [32]. Figure 13 shows the measured electrical power output and water-to-wire efficiency of the pico-scale Archimedes screw shown in Figure 5, as flow through the screw was varied [36]. The efficiency of the screw was approximately constant until flow was reduced to half of the design flow. A minimum flow of $0.02 \mathrm{~m}^{3} / \mathrm{s}$ was needed to provide sufficient torque to operate the generator, which was the limiting factor in low flow operation. A variable speed generator 
that allowed operation with reduced screw rotation speed would increase low flow efficiency, although this would substantially increase system cost.

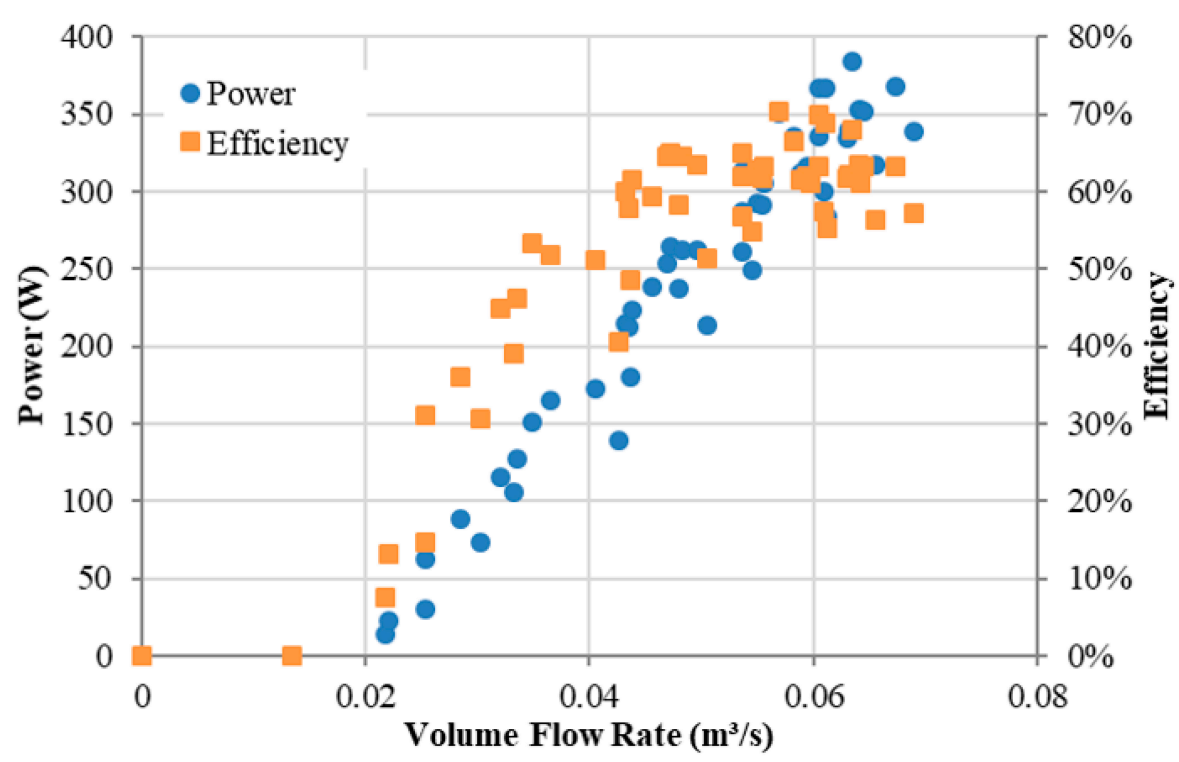

Figure 13. Power and efficiency (electrical output power/hydraulic power available) of a small Archimedes screw [36].

For fixed geometry reaction turbines, typically used in low head installations, the efficiency drops off dramatically when the turbine does not operate at its design point, as shown in Figure 10. When the flow rate changes from the design point, the flow field approaching the runner of a reaction turbine is changed. Therefore, the blade angles are not matched to the flow with a fixed geometry turbine runner, significantly reducing the turbine operating efficiency [59]. One option to solve this would be to use variable geometry inlets or runners, as in a full Kaplan or Francis turbine. However, these are mechanically complex at pico-scale, and would incur energy overheads which would render the system not economically viable [59]. (These are possible with Crossflow turbines due to the simplicity of the nozzle mechanism, requiring a single vane.) A simpler option would be to change the runner, with one runner during the low flow period and a second for the higher flow season. This would allow the turbine to operate more efficiently throughout the year and increase overall energy generation. For a site at Magdalena, Peru, a propeller turbine was designed for a $4 \mathrm{~m}$ head with a scroll casing, but no guide vanes. The original runner, Figure 14A, only worked well when flows were above $290 \mathrm{~L} / \mathrm{s}$, giving a shaft power output of $6.1 \mathrm{~kW}$. A second runner, Figure 14B, was designed for lower flow rates giving $5.3 \mathrm{~kW}$ at $180 \mathrm{~L} / \mathrm{s}$. This demonstrates the potential for using different runners, designed for different flow rates, within the same casing [60]. 
(A)

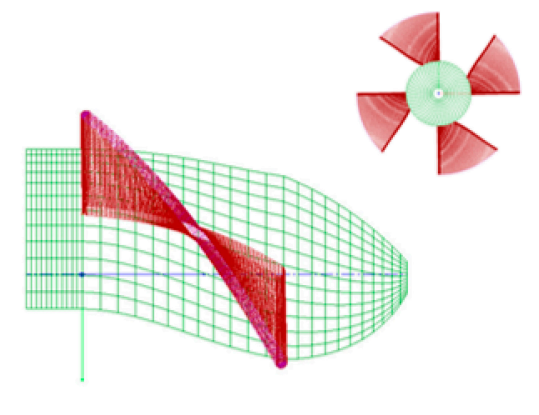

(B)

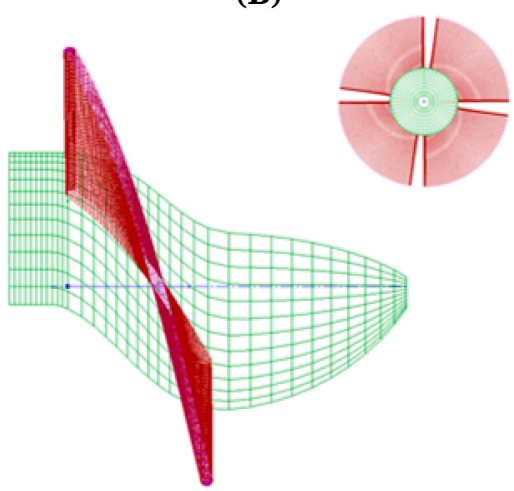

Figure 14. Runners for the same casing (A) original, high flow design and (B) redesigned for lower flow [60].

As the flow rate changes, the rotational speed of the turbine at maximum power will also change. Pico-hydropower schemes often directly feed AC loads. This requires good generator control, maintaining the rotational speed to obtain the appropriate grid frequency and voltage at the output terminals. Mechanical governors were found to be often unreliable and almost as expensive as the generator themselves [61]. A common control solution in pico-hydro systems is to use an Electronic Load Controller (ELC) to control the output voltage and frequency by varying the load on the turbine [62]. Changes in speed will cause the turbine to generate maximum power away from the rated output frequency. Therefore, it may be necessary to decouple the turbine rotational speed and the output frequency and voltage of the system. This can be achieved by using a DC generator or rectifier and an inverter to connect the turbine to the load. This has been suggested in a number of papers, with simulations carried out [63], but there are very few examples of implementations of this approach in literature [64]. There are some products on the market, such as the PowerSpout turbine family [21], that offer a grid connected model which has an inverter on the output. It is also possible to operate variable speed turbines by rectifying the generator output and connecting to a battery bank, either feeding DC loads, or using a stand-alone inverter [65], which can utilise maximum power point tracking algorithms to run the turbine at the peak power condition.

There are several different technical solutions to adapt to flow variability, from adapting the turbine to utilising power across a range of rotational speeds using power electronics. Additional energy can be extracted under variable environmental conditions at minimal additional cost or system complexity, where previously a turbine would have either been specified smaller or would not be able operate all year around. These solutions allow the turbine systems to be used across a range of conditions either through seasonal flow changes or different sites, 
enabling more power to be generated and therefore making the system more financially viable. This is discussed more in the following section.

\section{LOW POWER AND CAPACITY FACTOR}

The key to achieving a sustainable energy system is to ensure that there are not only domestic loads on the system, but also loads that generate income [66]. In micro hydropower and other off-grid schemes this may be accomplished by providing power to equipment that adds value to locally produced raw materials, such as those shown in Figure 15 This equipment can improve the efficiency of work practices and so provides additional income or time for the community. The initial investment for a pico-hydropower system can be made either directly by the local community, such as Vietnam [23] or supported through grants and subsidies from local authorities, such as the subsidy programme run by the Government of Nepal [67]. A study of 24 micro-hydropower systems in Nepal evaluated technical, social and economic success and failure points within the systems [68,69]. It identified several key parameters for success of a project, such as the number of industrial and commercial loads fed by the system, maintenance quality and the use of trained operators. One major success factor was the number of industrial loads that were supported by the system, as this gave the management committee additional income and was able to increase the capacity factor.

(A)

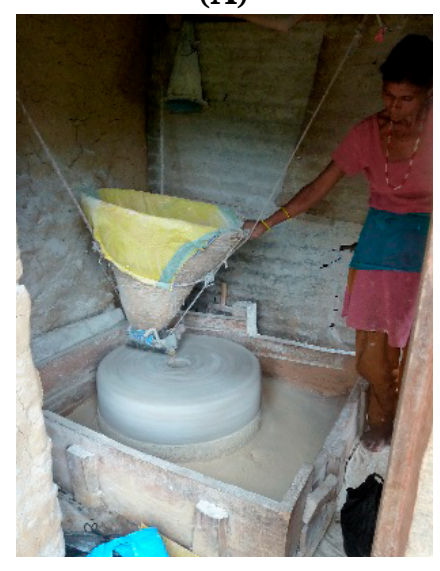

(B)

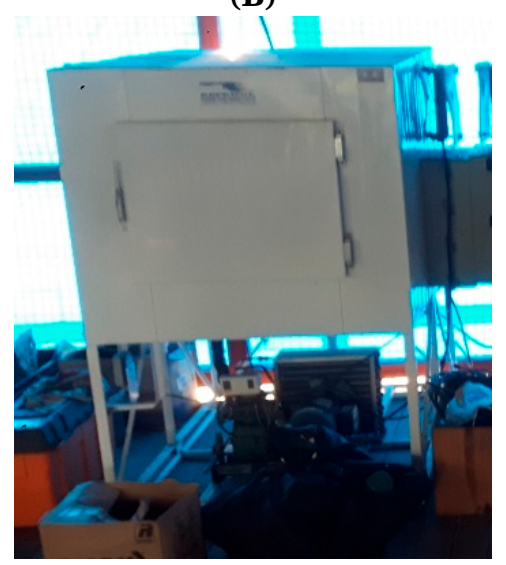

(C)

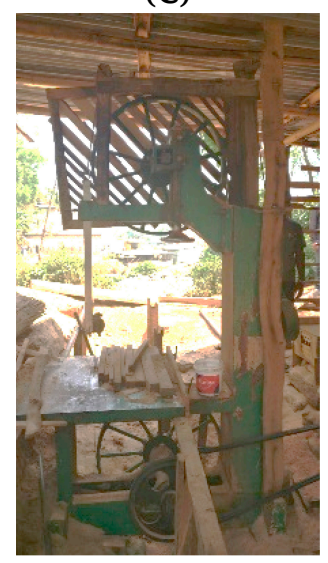

Figure 15. Potential income generating loads: (A) agricultural product processing, (B) ice-maker for fishermen, and (C) furniture workshop (Photo credit: (A) and (B) Sam Williamson, (C) Surendra Pandit, PEEDA).

However, pico-hydropower systems are typically too small to support many income generating loads. Machinery such as mills, rice polishers and hand tools use induction machines to do the work, which have large inrush currents on start-up, often up to 5 times that of their steady-state running. As they are loaded, they draw increasing amounts of current. Many pico-hydropower systems are less than $1 \mathrm{~kW}$. Therefore, it is normally only used for domestic loads. One option is to use a direct 
mechanical drive in the turbine house which, when operated in parallel with a generator and load controller, allows the turbine speed to still be controlled as long as it is not overloaded.

As rural domestic electricity consumers get used to using electrical power, and any economic benefit that it may bring, the number of electrical household items increases from lighting, to televisions, DVD players and refrigerators. Although electric cooking equipment is available, the power demand from this is incredibly high, and so often it is not used especially in rural areas [70]. Therefore, at peak times of the day, normally in the morning and evenings for domestic only loads systems, the voltage in the system drops, known as sagging. This effect can be seen in Figure 16. During the evening, the voltage sagged so much that the monitoring equipment was unable to measure the load. The sagging causes resistive loads to reduce their power consumption, so incandescent bulbs dim, and the result is often referred to as a brown-out. However, other types of loads behave differently. Modern equipment interfaced with power electronics are often constant power loads, and so as the voltage drops the current demand by the equipment increases, causing the voltage to drop further. If the current draw from the generator is too large, then the circuit protection trips, normally a circuit breaker located in the turbine powerhouse, causing the system to shut down. The reset of the circuit breaker then requires a visit to the powerhouse, which often is downhill, across difficult terrain.

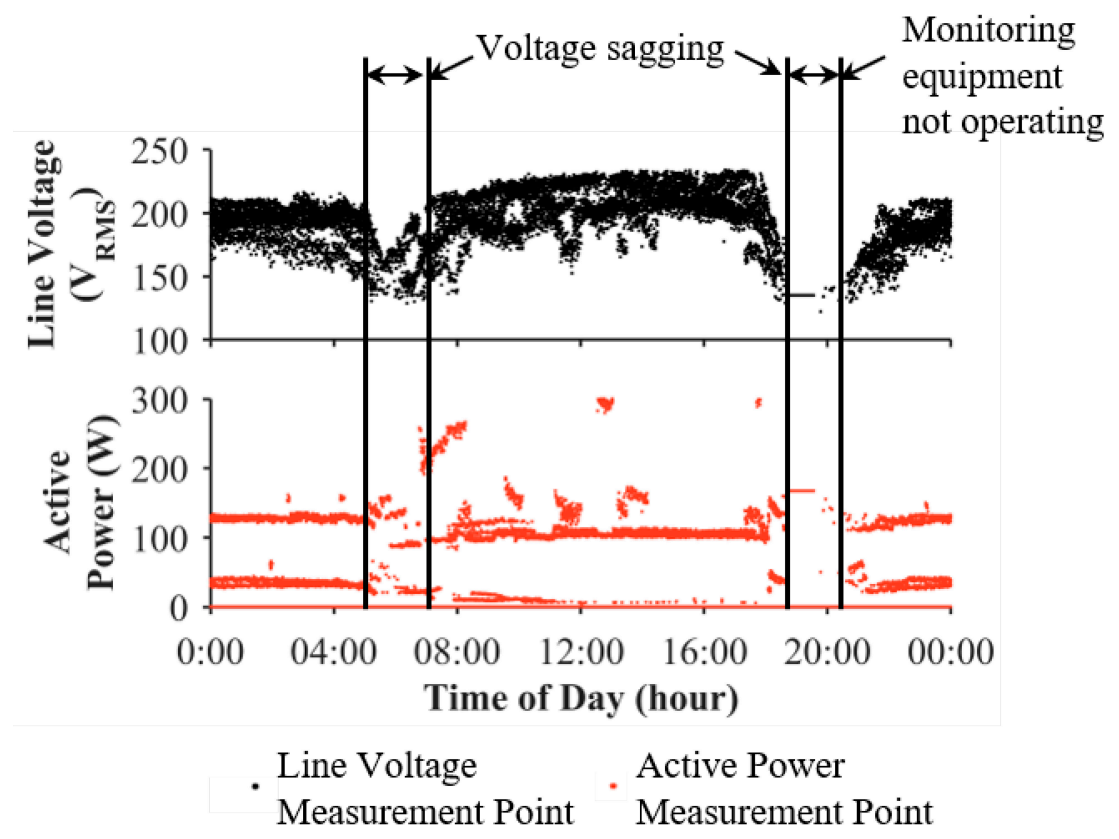

Figure 16. Line voltage and power demand on a pico-hydropower system in Nepal, measured over 5 days [71]. 
The capacity factor of a system is defined by the following equation:

$$
\text { Capacity Factor }=\text { Useful Output Power/Total Output Power }
$$

is a key metric to understand a system's viability. For small hydropower systems, the capacity factor can be as little as 20\% [72] and in the example measured in Figure 16 it was calculated to be around 30\%. This increases the overall cost of energy produced by the system, making it less financially viable. There is also a trade-off in designing a system. As previously shown in Figure 10, the flow varies across the year, a system can be designed to operate all year at maximum power, therefore the potential capacity factor could be high, but the overall output energy across the year is low. Alternatively, the system could be designed to be able to make use of the larger flow periods and with the ability to generate more power, but in the low flow season(s) the capacity factor would be much lower.

It is important to assess the financial impact of the capacity factor, flow variability and generator power limits at the design stage. If this is not carried out, especially with systems only able to supply residential loads, frequent demand overloads lead to power cuts and can cause a community to revert back to its previous energy sources. The electrical system then falls into disrepair and the initial investment in the system is wasted. However, there are social and technical solutions to overcome these issues.

Education and community cohesion are key components in ensuring the continuing viability of pico-hydropower electrical systems. Often when a pico-hydropower system is installed in a remote community, it is their first experience of grid level electrical power. Therefore, community members must be sensitised to the opportunities, constraints, and maintenance and servicing needs of the new electricity system. As can be seen in Figure 16, there are often two peaks in the demand in isolated communities; in the morning at breakfast time, and in the evening. Educating the community to only use necessary loads during this period will ensure that the system has less stress put on it. Typically, the longer a user has had access to electricity, the more consumption devices they have, which leads to continuing demand growth on the system [73]. Most pico-hydropower systems have a fixed capacity, and increased demand without careful use will either cause more frequent voltage dips or system overloads. Communities should therefore be educated in how to manage their demand to ensure this does not happen. For example, on the Isle of Eigg, Scotland, each household has a fixed consumption limit which they are not allowed to exceed, and the community electricity delivery company issues warnings when supply is low [74]. In some schemes in Kenya, India and elsewhere, simple load limiting devices have been implemented to restrict consumer demand [75]. 
Technical solutions are available to increase a system's capacity factor When a pico-hydropower system is overloaded, the ELC cannot maintain the voltage or frequency and the current exceeds the safe limit causing the circuit protection to trip. As previously discussed, the inrush current transient at start up for induction machines can cause the system to overload and the circuit breaker to trip. A novel ELC has been developed $[37,76]$ that allows the turbine speed to droop as a highly inductive load is attached, reducing the inrush current, and then slowly increases the rotational speed back to its nominal value (Figure 17). This has been shown to reduce the inrush current to 1.5 times its steady state value, reducing the demand on the hydropower system. These ELCs are now commercially available in Nepal [76].

(A)

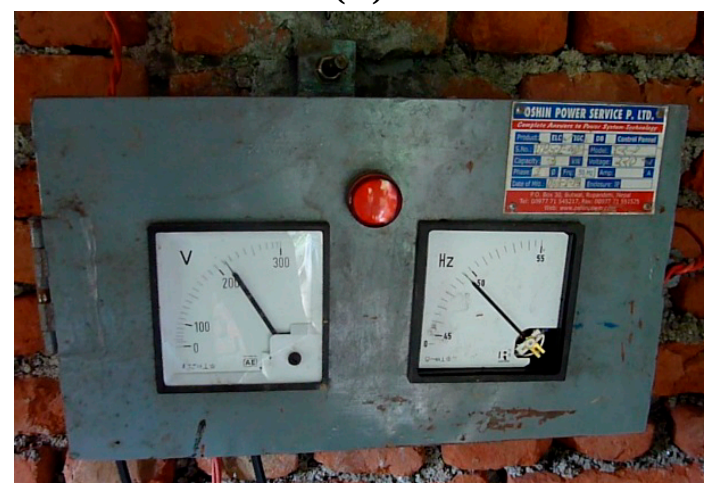

(B)

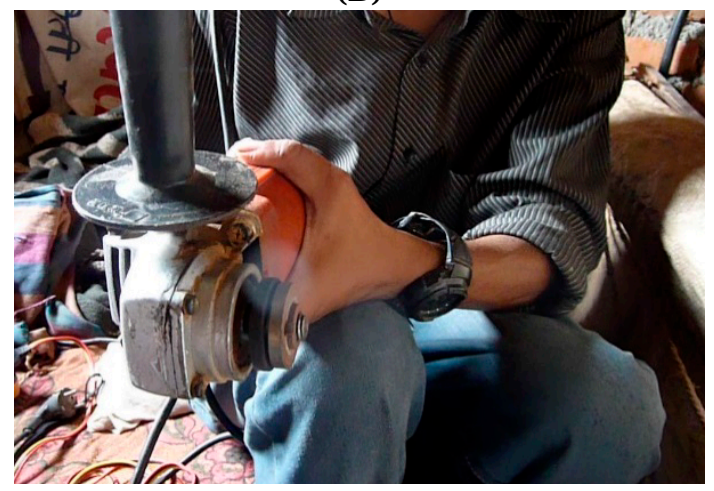

Figure 17. Photo of the (A) drooping ELC and (B) the output running an angle grinder (Photo credit: Sam Williamson).

An alternative approach to load control for use in cases where a village is supplied by a single generator has been developed and is known as a distributed electronic load controller (DELC) [77]; a schematic is shown in Figure 18. An individual DELC is installed at each household, and each household is assigned a power consumption. When the household load is below the assigned threshold, the DELC diverts the extra available current to a useful sink for the excess power, typically a load such as a water heater or rice cooker. A smaller ELC is still installed at the generator to accurately regulate the output voltage, but it does not have to take the full generator rating as the household DELCs absorb most of the excess load. One drawback to this system is that it still does not regulate household consumption, and so system overloads are still possible. However, it does provide some redundancy as there are several ELCs able to regulate the output if there is a failure in one of the switches. A further practical need is minimising the cost of producing individual DELCs for each household for the system to be economically viable in low income villages. 


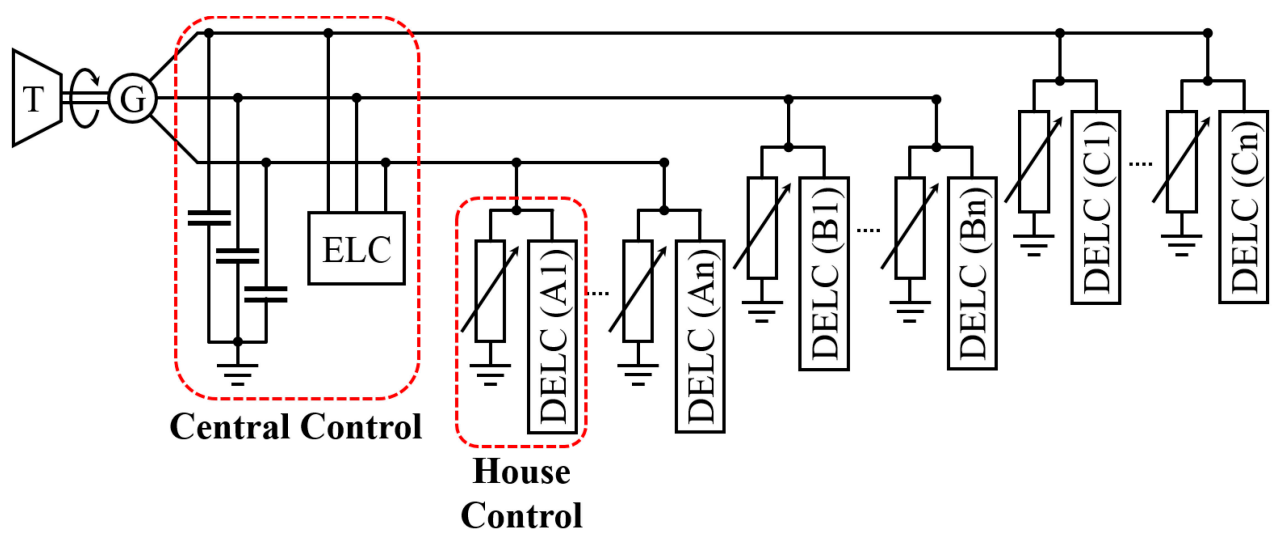

Figure 18. Schematic of distributed electronic load controller (redrawn from [77]).

Using the power from multiple interconnected pico-hydropower systems can enable income generating loads [78]. For the interconnected pico-hydropower network, the units are connected together using inverters to form a grid, Figure 19. The individual inverters use locally measured values to regulate the grid, and require no external control inputs to power flows between units and the loads. This provides a more reliable, redundant system, with the opportunity to feed larger loads and expand the system as capital allows. The inverter controller has been simulated and validated experimentally [63] but it has not yet been validated in full-scale hardware tests.

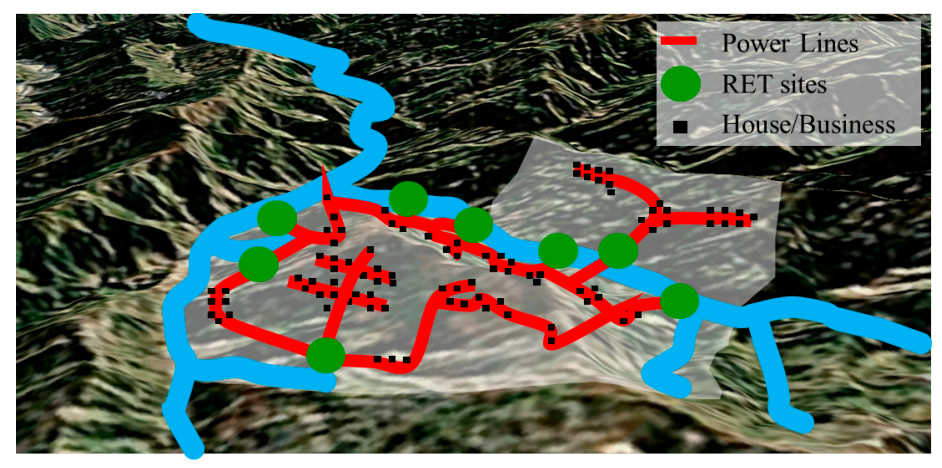

Figure 19. Interconnected pico-hydropower off-grid network concept, linking multiple pico-hydropower turbines together for a larger grid output power [78].

The capacity factor of a pico-hydropower system can be increased by usefully using the dumped load from the ELC. This energy could be used to heat water for a communal source, power an ice-maker to preserve produce or pump water at times of low demand for drinking or irrigation purposes. The energy could also be stored in batteries [79] or other storage technology such as a fuel cells [80] (although it should be noted this is currently not appropriate for rural integration), to be fed back into the system during times of high demand. This technique would allow loads larger than the turbine capacity to be connected onto the grid for short periods or time, and reduce the number of overloading incidents. It has been proposed that an Internet-of-Things-based system [81] could be 
used to manage loads on the ELC, providing useful community-based loads such as heating or light for greenhouses.

For the financial viability of pico-hydropower systems, the capacity factor has to be as high as possible, so all generated power is being usefully consumed. This can be technologically enabled by using intelligent or distributed loads, storage elements within the control system or interconnected pico-hydropower units. Alongside this, raising awareness of times of high demand and low demand within communities can support consumers to choose when to use power, reducing voltage sagging events.

\section{LOCAL MANUFACTURE IN DEVELOPING COUNTRIES}

Pico-hydropower turbines can either be built locally, mass manufactured and imported, or a mixture of the two with some components locally sourced and others imported. This choice is also available with small wind turbines, although often locally made wind turbines are able to be built in even more basic workshops using reclaimed materials and require less accuracy in manufacture [82]. Mass manufactured pico-hydropower turbines are generally perceived to have an optimised and efficient design and good build quality. Economies of scale provide the potential to reduce the cost per unit. However, mass manufactured units require specific environmental conditions for efficient operation, so the site must be modified for the turbine. Some turbine designs are able to be manufactured in country. There are several advantages to this, boosting the local economy and capacity building [82], knowledge of how to maintain and service the system locally, and it has been identified as an essential aspect for successful pico-hydropower projects in several central African countries [83]. The Hydro Empowerment Network (HPNET) have supported this approach, providing a forum to share good practice and to transfer successful technology between countries with similar rural energy needs in South and South-East Asia [84].

Basic local workshops that are able to manufacture and repair pico-hydropower turbines need facilities to cut, form and weld steel, a lathe to turn parts, and a pillar drill. The designs of turbines need to recognise the limitations of the workshops, and not require complex machining or large component/assembly machining. Often, tolerances are closer for hydropower turbine machinery than wind turbines, so the technicians are required to be reasonably skilled to produce good local hydro systems. Short case studies of designs that are made for local manufacture in simplified workshops are discussed below. These examples provide a basis to develop rules for redesigning pico-hydropower turbines so they can be manufactured in local workshops with local labour. 


\section{Pico Power Pack}

The Pico Power Pack [17] is a design of Pelton Turbine with a directly-driven induction generator, Figure 20. The development of the design is described in detail in [50]. The objective of the design was to enable ease of manufacture while maintaining good performance. The main features that distinguish the design are: horizontal shaft, with the runner attached to a shaft extension from the generator; fixed nozzle; removable casing; buckets suitable for relatively high flow rates which are cast individually and bolted to the runner. The chosen runner geometry was designed for high performance, but without compromising strength or reliability.

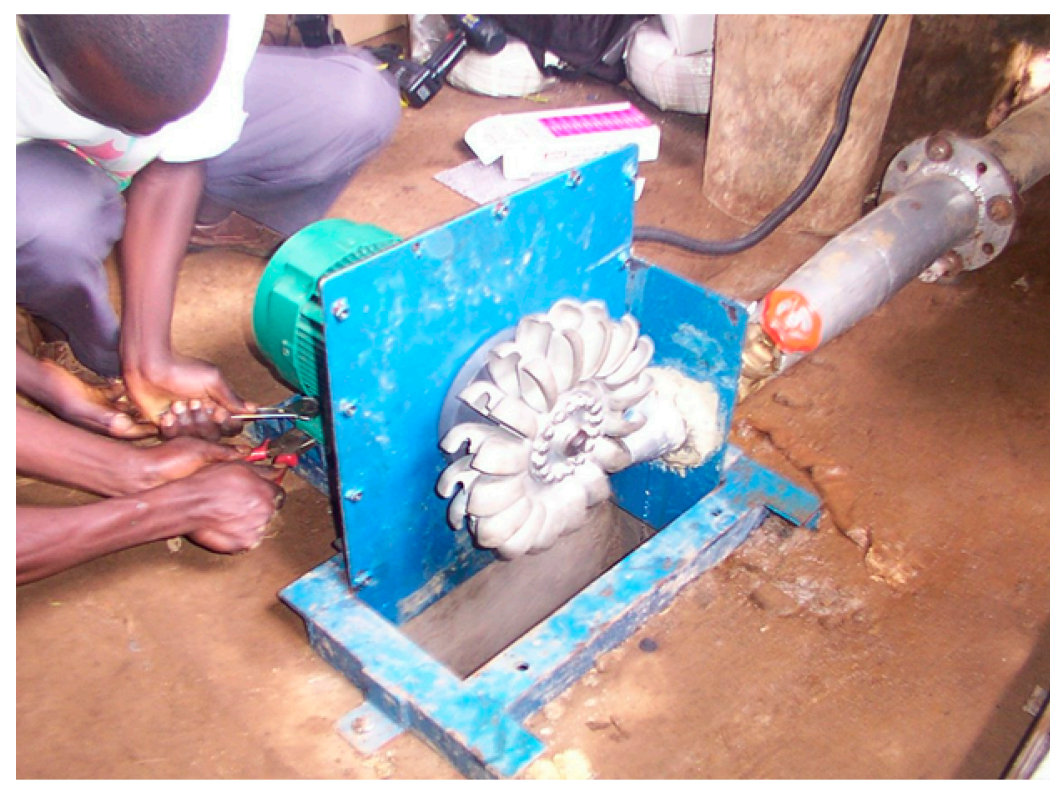

Figure 20. Pico Power Pack with casing removed (Photo credit: Phil Maher, Hydromatch Ltd.).

Detailed guidelines for manufacturing the Pico Power Pack are available freely on the web [85] and were disseminated through training courses run in Asia, Africa and Latin America. Variations of the design are now being produced by a number of manufacturers in different countries, including Nepal (Power Tech), Peru (Tepersac), Indonesia (PT Heksa and Protel Multi Energy). Turbines of this design have been imported from Peru to the UK for use on small $(<5 \mathrm{~kW})$ grid-connected schemes, or replicated on a Do-it-yourself basis [86].

\section{Locally Manufactured Crossflow Turbines}

The Crossflow turbine developed by Banki and Michell [87] independently at the beginning of the 20th century has many qualities that make it suitable for manufacture in basic workshops. The runner and casing can be made from sheet metal, with the runner blades either formed or made from pipe, and the components welded and bolted together. Since the mid-1970s, simplified versions of Crossflow turbines have been used across the developing world to provide rural 
electrification [13], becoming ubiquitous at low to medium heads due to their simple manufacturing and ability to manage a range of heads and flows. The Crossflow turbine can also be adapted for a wide variety of heads and flows, leading to variation in turbine aspect ratios. The base-level design for these turbines was developed by the Swiss Centre for Appropriate Technology (SKAT) and other international development agencies, which has passed through more than 15 iterations over the past 40 years [27,88]. Although often used at the micro-hydropower scale, these Crossflow turbines can still be used at the pico scale, such as the example from Nepal shown in Figure 21, the Indonesian Entec TP100 [89,90], or the Remote Hydrolight Traditional Mill and Hindu Kush Turbines [91].

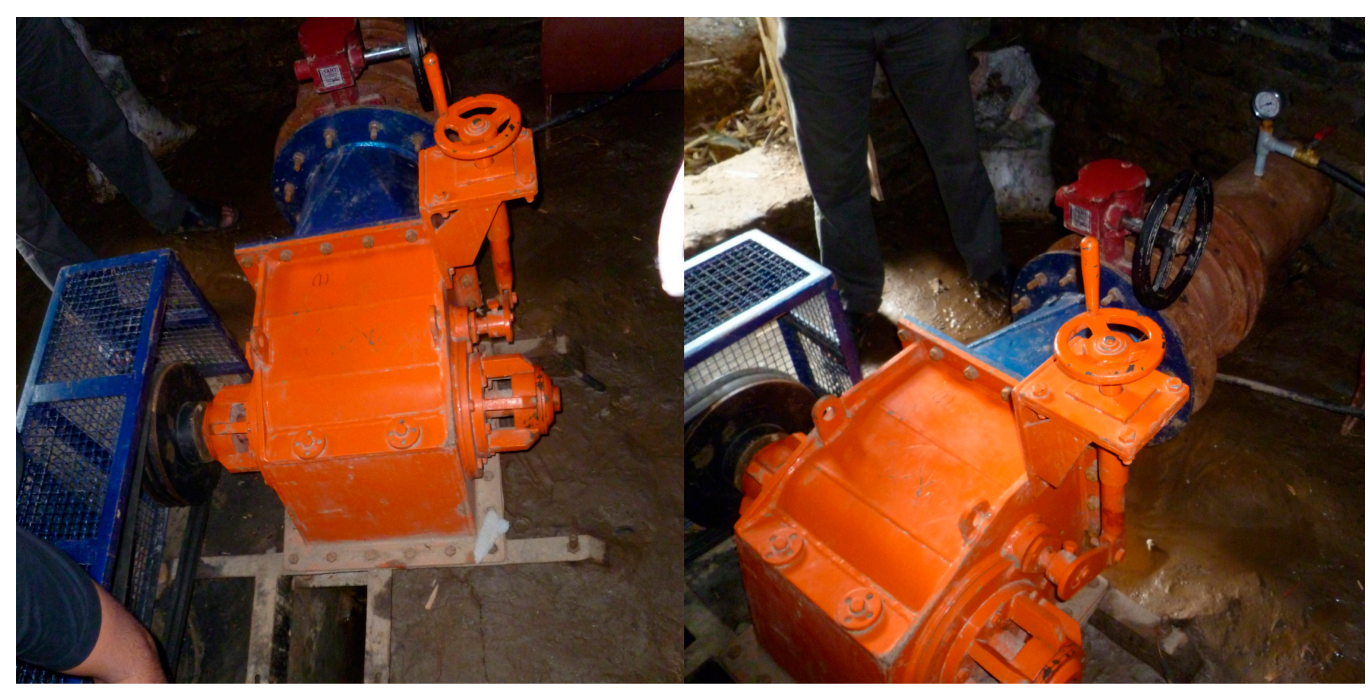

Figure 21. 5 kW Nepali-made Crossflow turbine (Photo credit: Sam Williamson).

Alongside the SKAT crossflow turbines, other designs have been used at small scale. The "Firefly" turbine was developed for use in the Philippines to charge batteries at $12 \mathrm{~V}$ [92]. It was designed to be made in simple workshops, using a car alternator to generate the power. There are no complex machining processes required in manufacturing the turbine, and the runner blades can either be made from bent sheet or cut sections of tube. The matching between the turbine and the alternator is critical and was found to reduce the system efficiency greatly [93]. Modifying the turbine design to run at a higher speed or changing the alternator to a low speed version can improve the overall system efficiency.

\section{Giddens/PT Series Turbine}

The turbines proposed by Alexander and Giddens [94] and the PT series turbines [36] are low head propeller turbines that have been designed to be manufactured in basic workshop environments. The turbine runners, casings and supports can all be made from cold rolled sheet and rod stock material. A method of manufacturing the complex 
runners was developed by [94] where a fixed flat guide is placed next to the runner hub, and the blade cut out of sheet metal is then welded onto the hub, as shown in Figure 22A, with the final finished runner shown in Figure 22B. These simplified methods of manufacture can reduce the efficiency of operation but allow the turbines to be manufactured and repaired in a much larger number of workshops, and reducing the cost of manufacture.

(A)

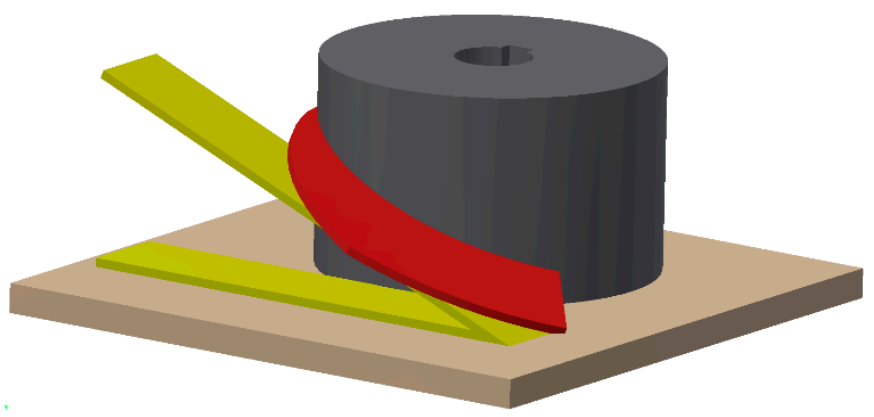

(B)

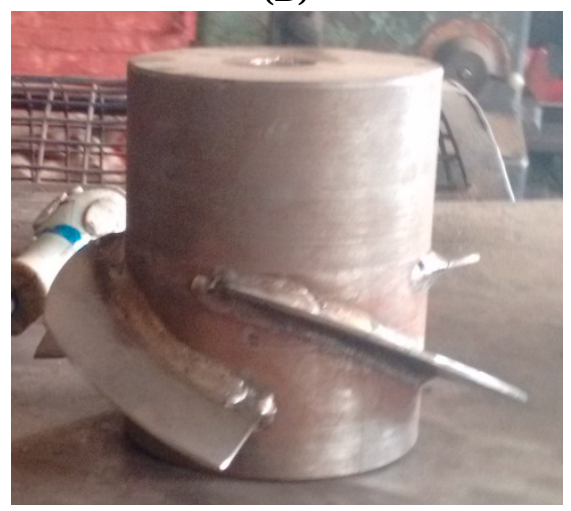

Figure 22. (A) Method of manufacturing the runner using a flat guide. (B) The final runner for a propeller turbine made in a local basic workshop (Photo credit: Joe Butchers).

The PT series turbine was initially designed to be manufactured using a lathe with a large centre height to produce the volute casing and runner housing, which can normally only be done in very large machine shops. However, design and assembly changes were implemented to allow the runner housing to be machined prior to insertion into the volute casing, saving time and money in manufacture, with only a small reduction in efficiency [95]. This design change enabled the turbine to be manufactured in a much larger number of workshops.

\section{Locally Manufactured Archimedes Screw Turbine}

A Japanese team designed and built an Archimedes Screw type turbine in Tanzania using locally available materials in a small workshop [96]. The turbine was constructed from a steel shaft with ribs welded onto it. The blades were fabricated from a steel mesh formed around the ribs, onto which a glass-fibre coating and resin was applied. This was placed in a rolled sheet steel trough and supported in a frame. To increase the rotational speed of the output, motorcycle sprockets and chains were used to connect the output of the runner with a car alternator, which was then used to charge lead acid batteries. Although the reported power output from this turbine was low, at around $25 \mathrm{~W}$, with a large amount of labour required to build it and a cost of $\$ 460$, this design would be able to be manufactured in local workshops very readily. With analysis of the design and set-up, matching the speed of the generator and turbine and 
better understanding of the electrical system, the power output of this turbine could most likely be increased.

\section{Low Head Turgo Turbine}

The low head Turgo turbine runner developed in Bristol [38] has the potential to be made in basic workshops. Turgo runners are normally thought to require complex casting production, however using the simple Turgo cup design, these can be redesigned to be cast, fabricated from steel or carved from wood, as shown in Figure 23. The fabricated steel cup used a concrete die to form the cup shape. The carved cup would be able to be hand carved, utilising skills available in many developing countries. In hydrodynamic tests it was found that all cups had similar performance [97]. However during strength tests it was found that the wooden cup failed much earlier than the fabricated steel, due to the anisotropic grain structure and inferior mechanical properties they exhibit. These mechanical properties would degrade further with water absorption which could be mitigated through sealing or painting the cups.

(A)

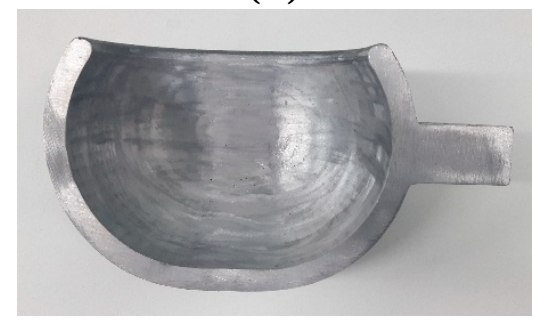

(B)

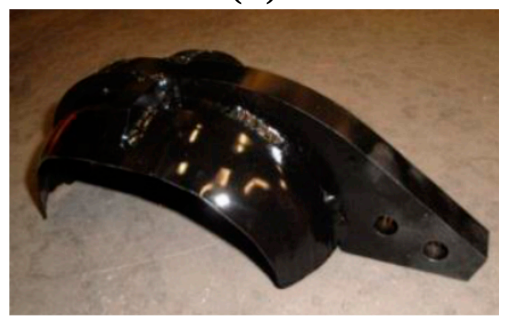

(C)

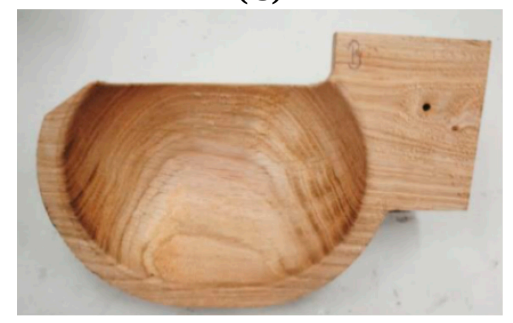

Figure 23. Low head Turgo cups scaled for a $1 \mathrm{~kW}$ runner at $3.5 \mathrm{~m}$ head made from (A) cast aluminium, (B) fabricated steel, and (C) carved wood (Photo credit: Joe Butchers).

\section{Generalised Design Rules for Local Manufacture}

Using the examples above, eight design rules can be drawn out for local manufacture of pico-hydropower turbines.

1. Turbines should be designed to use simple stock material: sheet, rod, angle and tube sections made from cold rolled or drawn steel. This can be formed through bending and shaped to obtain the required profiles.

2. The manufactured shapes should be simple, with no re-entrant features.

3. Manufacturing processes such as bending, turning, welding, drilling, and casting where required, should only be used. Basic tools and tooling must only be required.

4. The size of component that is required to be turned should be minimised where possible to allow the manufacturing to take place on smaller machines. 
5. Electrical equipment should be sourced from readily available designs, such as induction machines or car alternators. However, careful design is required to make sure the turbine and generator match well to obtain the maximum possible efficiency.

6. Jigs should be used to improve accuracy, especially on critical components such as reaction runners. Their design and implementation should be part of the initial design procedure.

7. Designs can be scaled through non-dimensional analysis, allowing the turbine design to be applied in several different environmental conditions.

8. As with many design for manufacture rules, adjustment should be able to be made to the system once built, no special tools should be required to build the system, and standard components should be used wherever possible [98].

These design rules can be used with wider design implementation concepts such as the nine principles [99], which provide a strong contextual overview into how to improve design for smaller workshops and how to localise designs for the environment it operates within. Through this, more appropriate designs for pico-hydropower systems can be developed and manufactured in-country enabling a more resilient supply chain, and better social acceptance from the local population.

\section{DISCUSSION}

There are technical solutions to address each of the main challenges identified, with some requiring more development and research to achieve commercialisation. However, each of the challenges require social, economic and policy developments alongside the technical progress to enable future success of pico-hydropower systems. There are three key non-technical enablers identified in these challenges:

- Understanding of the local context and regional support groups: The environments that pico-hydropower systems are installed in are different from country to country. Therefore, understanding the local context in terms of physical and social environment is imperative to ensure success of a project. This can be translated into technical design changes, enabling policy development, cultural appropriation of solutions, and understanding social acceptance of technology. This also extends to local manufacturing practices. Regional support networks can also provide important knowledge sharing across geographic regions, enabling new ideas, designs and solutions to be exchanged across technical, social, economic, cultural and policy domains.

- Supporting system industrial loads to ensure financial security: A high capacity factor of a plant enables more of the power generated to be charged for. This could either provide a strong maintenance and operation fund for the operator or reduce cost for users. With this 
designed in from the beginning of the project, this allows a more financially secure system to develop and gives consumer the confidence to rely on the system.

- Raising awareness amongst the appropriate stakeholder groups: Promotion of technology and ideas with the stakeholder groups is critical for successful introduction of a technology. Vendors and installers must be made of aware the technology and understand their benefits and drawbacks, to be able to promote and sell them to individuals and communities. Policy makers may need to alter policy to allow new technology to receive incentives similar technology has access to.

\section{CONCLUSION}

This paper has identified and discussed four main challenges with pico-hydropower: lack of low head solutions, ability to deal with variable water flow rates, use of income generating loads on pico-hydropower systems and the ability to locally manufacture and maintain turbines. For each of these challenges, there are solutions that are currently available or under research that can overcome them. Low-head sources are prevalent in many countries, with both locally manufactured and mass-produced solutions available for these conditions. Three critical components for success in a pico-hydropower implementation are: understanding the local context; the ability to generate income from the energy provided; awareness and knowledge of technology amongst stakeholders. Firstly, local context in terms of environment, social and cultural norms, and economic and policy background enables technology to be most appropriately applied to the situation. Using locally manufactured options provides a strong option for a more resilient supply chain, keeping knowledge of the systems in the region, and enables local adaptations of designs for the environment. Secondly, a strong operational plan during the design phase is key to the success of the system. Income generation and financial viability ensure that a system can continue to operate successfully, increasing the amount of useful energy consumed. Finally, all stakeholders also need to be aware of new technology to understand how it fits and can be adapted to their context.

\section{CONFLICTS OF INTEREST}

The authors declare that there is no conflict of interest.

\section{REFERENCES}

1. UN Sustainable Development Goals. Available from: https://sustainabledevelopment.un.org/. Accessed 2019 Sep 30. 
2. McCollum DL, Echeverri LG, Busch S, Pachauri S, Parkinson S, Rogelj J, et al. Connecting the sustainable development goals by their energy inter-linkages. Environ Res Lett. 2018;13:033006.

3. Nerini FF, Tomei J, To LS, Bisaga I, Parikh P, Black M, et al. Mapping synergies and trade-offs between energy and the Sustainable Development Goals. Nat Energy. 2018;3:10-5.

4. UN Sustainable Energy for All Initiative. Available from: http://www.se4all.org. Accessed 2019 Sep 30.

5. United Nations Economic and Social Council. Special edition: progress towards the Sustainable Development Goals. Report of the Secretary-General. New York (US): United Nations Economic and Social Council; 2019. Document E/2019/68. Available from: https://undocs.org/E/2019/68. Accessed 2019 Sep 30.

6. International Energy Agency. World Energy Outlook 2016. Paris (France): IEA; 2016.

7. Alstone P, Gershenson D, Kammen DM. Decentralized energy systems for clean electricity access. Nat Clim Change. 2015;5:305-14.

8. Kirubi C, Jacobson A, Kammen DM, Mills A. Community-Based Electric Micro-Grids Can Contribute to Rural Development: Evidence from Kenya. World Dev. 2009;37:1208-21.

9. Nerini FF, Howells M, Bazilian M, Gomez MF. Rural electrification options in the Brazilian Amazon: A multi-criteria analysis. Energy Sustain Dev. 2014;20:36-48

10. Kalbande SR, More GR, Nadre RG. Biodiesel Production from Non-edible Oils of Jatropha and Karanj for Utilization in Electrical Generator. BioEnergy Res. 2008;1:170-8.

11. Maher P, Smith N. Pico hydro for village power: A practical manual for schemes up to $5 \mathrm{~kW}$ in hilly areas. 2nd ed. London (UK): Department for International Development; 2001.

12. Williamson SJ, Stark BH, Booker JD. Low head pico hydro turbine selection using a multi-criteria analysis. Renew Energy. 2014;61:43-50.

13. Paish O. Micro-hydropower: status and prospects. Proc Inst Mech Eng A J Power Energy. 2002;216:31-40.

14. Senior J, Saenger N, Müller G. New hydropower converters for very low-head differences. J Hydraul Res. 2010;48:703-14.

15. Date A, Akbarzadeh A. Design and cost analysis of low head simple reaction hydro turbine for remote area power supply. Renew Energy. 2009;34:409-15.

16. Sumanik Leary J, Delor M, Little M, Bellamy M, Williams A, Williamson S. Engineering in Development: Energy. London (UK): Engineers Without Borders UK; 2014.

17. Maher P, Smith N. The Pico Power Pack: a new design for pico hydro. Pico Hydro. 1999;no.7. Available from: http://www.eee.nottingham.ac.uk/ picohydro/docs/NepalCaseStudy tech.pdf. Accessed 2019 Sep 30.

18. Department of Hydrology and Meteorology. Streamflow Summary (1962-2006). Kathmandu (Nepal): Government of Nepal; 2008. 
19. Meier T, Fischer G. Assessment of the Pico and Micro-Hydropower Market in Rwanda. Nairobi (Kenya): GVEP; December 2011.

20. Powerpal website. Available from: http://www.powerpal.com. Accessed 2019 Sep 30.

21. Powerspout website. Available from: http://www.powerspout.com. Accessed 2019 Sep 30.

22. Energy Systems and Design website. Available from: http://www.microhydropower.com. Accessed 2019 Sep 30.

23. International Solar Energy Society. Rural Energy Supply Models-RESuM, Executive Summary. Freiburg im Breisgau (Germany): International Solar Energy Society; 2001. Available from: http://siteresources.worldbank.org/ EXTRENENERGYTK/Resources/5138246-1237906527727/Rural0Energy0Suppl y0Models010RESuM.pdf. Accessed 2019 Sep 30.

24. Smits M, Bush SR. A light left in the dark: The practice and politics of pico-hydropower in the Lao PDR. Energy Policy. 2010;38:116-27.

25. Susanto J. Local installation methods for low head pico-hydropower in the Lao PDR. Renew Energy. 2012;44:439-47.

26. Ossberger website. Available from: http://www.ossberger.de. Accessed 2019 Sep 30.

27. Ghimire A, Dahal DR, Pokharel N, Chitrakar S, Thapa BS, Thapa B. Opportunities and Challenges of introducing Francis Turbine in Nepalese Micro Hydropower Projects. J Phys Conf Ser. 2019;1266:conference 1.

28. Waters S, Aggidis GA. Over 2000 years in review: Revival of the Archimedes screw from pump to turbine. Renew Sustain Energy Rev. 2015;51:497-505.

29. Brada K. Wasserkraftschnecke ermöglicht Stromerzeugung über Kleinkraftwerke (Hydroelectric Power Generation on Small Screws allows Power Plants). Maschinenmarkt. 1999;105(4):52-6. German.

30. Nuernbergk DM. Berechnung und optimaler Entwurf von archimedischen Schnecken als Wasserkraftmaschine (Calculation and optimal design of Archimedian Screws as a Hydroelectric Generator). Detmold (Germany): Verlag Moritz Schäfer; 2012. German.

31. Koetsier T, Blauwendraat H. The Archimedean Screw-Pump: A Note on its Invention and the Development of the Theory. In: Cassino $\mathrm{M}$, editor. International Symposium on the History of Machines and Mechanisms. Berlin (Germany): Springer; 2004. p. 181-94.

32. Lashofer A, Hawle W, Kampel I, Kaltenberger F, Pelikan B. State of Technology And Design Guidelines For The Archimedes Screw Turbine. In: Proceeding of Hydro 2012-Innovative Approaches to Global Challenges; 2012 Oct 29-31; Bilbao, Spain.

33. Fishtek Consulting. Fish Monitoring and Live Fish Trials: Archimedes Screw Turbine, River Dart. Dartington (UK): Fishtek Consulting; 2007. Available from: http://www.mannpower-hydro.co.uk/wp-content/uploads/2016/04/Phase-1-ar chimedean-screw-fish-passage-test-results.pdf. Accessed 2019 Sep 30.

34. Lubitz WD, Lyons M, Simmons S. Performance Model of Archimedes Screw Hydro Turbines with Variable Fill Level. J Hydraul Eng. 2014;140. 
35. Rohmer J, Knittel D, Sturtzer G, Flieller D, Renaud J. Modeling and experimental results of an Archimedes screw turbine. Renew Energy. 2016;94:136-46.

36. Lyons MWK. Lab Testing and Modeling of Archimedes Screw Turbines [thesis]. Guelph (Canada): University of Guelph; 2014. Available from: https://atrium.lib.uoguelph.ca/xmlui/handle/10214/8647. Accessed 2019 Sep 30.

37. Gautam B. Low Head Pico-Hydro: A Robust Rural Renewable Energy Technology for Remote Rural Areas. Hydro Nepal J Water Energy Environ. 2011;11:64-6.

38. Bhaukajee J. Report on $1 \mathrm{~kW}$ Propeller Turbine Test at Turbine Testing Lab, Kathmandu. Kathmandu (Nepal): PEEDA; 2014.

39. Williamson SJ, Stark BH, Booker JD. Performance of a low-head pico-hydro Turgo turbine. Appl Energy. 2013;102:1114-26.

40. Williamson SJ, Booker JD, Stark BH. Site Implementation of a Low-Head Pico-Hydro Turgo Turbine. In: Sayigh A, editor. Renewable Energy in the Service of Mankind. Vol 1. Berlin (Germany): Springer; 2015. p. 329-38.

41. Zotlöterer website. Available from: http://www.zotloeterer.com. Accessed 2019 Sep 30.

42. Dhakal S, Timilsina AB, Dhakal R, Fuyal D, Bajracharya TR, Pandit HP, et al. Comparison of cylindrical and conical basins with optimum position of runner: Gravitational water vortex power plant. Renew Sustain Energy Rev. 2015;48:662-9.

43. Alzamora Guzmán VJ, Glasscock JA, Whitehouse F. Design and construction of an off-grid gravitational vortex hydropower plant: A case study in rural Peru. Sustain Energy Tech Assess. 2019;35:131-8.

44. Dhakal R, Nepal A, Acharya A, Kumal B, Aryal T, Williamson SJ, et al. Technical and economic prospects for the site implementation of a gravitational water vortex power plant in Nepal. In: Proceedings of International Conference on Renewable Energy Research Applications; 2016 Nov 20-23; Birmingham, UK. Piscataway (US): IEEE; 2017. p. 1001-6.

45. Power C, McNabola A, Coughlan P. A Parametric Experimental Investigation of the Operating Conditions of Gravitational Vortex Hydropower (GVHP). J Clean Energy Tech. 2016;4:112-9.

46. Wiemann P, Müller G, Senior J. Review of current developments in low head, small hydropower. In: Proceedings of 32nd IAHR Conference; 2007 Jul 1-6; Venice, Italy.

47. Centre for Ecology and Hydrology, UK. Available from: http://www.ceh.ac.uk. Accessed 2019 Sep 30.

48. Müller G, Kauppert K. Performance characteristics of water wheels. J Hydraul Res. 2004;42:451-60.

49. Muller GU, Wolter C. The breast shot water wheel: design and model tests. Proc Inst Civ Eng Eng Sustain. 2004;157:203-11.

50. Gilbert Gilkes and Gordon website. Available from: http://www.gilkes.com/Hydropower. Accessed 2019 Sep 30. 
51. Harvey A, Brown A, Hettiarachi P, Inversin A. Micro Hydro Design Manual. Rugby (UK): ITDG Publishing; 1993.

52. Williams AA, Simpson R. Pico hydro-Reducing technical risks for rural electrification. Renew Energy. 2009;34:1985-91.

53. Quaranta E, Revelli R. Output power and power losses estimation for an overshot water wheel. Renew Energy. 2015;83:979-87.

54. Quaranta E, Muller G. Sagebien and Zuppinger water wheels for low head hydropower applications. J Hydraul Res. 2018;56:526-36.

55. Quaranta E, Revelli R. Gravity water wheels as a micro hydropower energy source: A review based on historic data, design methods, efficiencies and modern optimizations. Renew Sustain Energy Rev. 2018;97:414-27.

56. Lyons M, Lubitz WD. Archimedes screws for microhydro power generation. In: Proceedings ASME 7th International Conference on Energy Sustainability; 2013 Jul 14-19; Minneapolis, USA. New York (US): ASME; 2013.

57. Hawle W, Lashofer A, Pelikan B. Lab Testing of the Archimedean Screw. In: Proceedings Hidroenergia Conference; 2012 May 23-26; Wroclaw, Poland.

58. Kozyn AJ. Power Loss Model for Archimedes Screw Turbines [thesis]. Guelph (Canada): University of Guelph; 2016.

59. Singh P, Nestmann F. Experimental optimization of a free vortex propeller runner for micro hydro application. Exp Therm Fluid Sci. 2009;33:991-1002.

60. Simpson RG, Williams AA. Application of computational fluid dynamics to the design of pico propeller turbines. In: Proceedings of the International Conference on Renewable Energy for Developing Countries; 2006 Apr 5-7; Washington DC, USA.

61. Henderson D. An advanced electronic load governor for control of micro hydroelectric generation. IEEE Trans Energy Conver. 1998;13:300-4.

62. Smith NPA. Induction generators for stand-alone micro-hydro systems. In: Proceedings of International Conference on Power Electronics, Drives and Energy Systems for Industrial Growth; 1996 Jan 8-11; New Delhi, India. Piscataway (US): IEEE; 2002. p. 669-73.

63. Williamson SJ, Griffo A, Stark BH, Booker JD. A controller for single-phase parallel inverters in a variable head pico-hydropower off-grid network. Sustain Energy Grids Networks. 2016;5:114-24.

64. Márquez JL, Molina MG, Pacas JM. Dynamic modeling, simulation and control design of an advanced micro-hydro power plant for distributed generation applications. Int J Hydrogen Energy. 2010;35:5772-7.

65. Leite V, Couto J, Ferreira Â, Batista J. A Practical Approach for Grid-connected Pico-hydro Systems using Conventional Photovoltaic Inverters. In: Proceedings IEEE International Energy Conference; 2016 Apr 4-8; Leuven, Belgium. Piscataway (US): IEEE; 2016.

66. Hong GW, Abe N. Sustainability assessment of renewable energy projects for off-grid rural electrification: The Pangan-an Island case in the Philippines. Renew Sustain Energy Rev. 2012;16:54-64.

67. Ministry of Population and Environment. Renewable Energy Subsidy Policy, 2073 BS. Kathmandu (Nepal): Government of Nepal; May 2016. 
68. Butchers J, Williamson S, Booker J, Tran A, Gautam B, Bikram Karki P. A study of micro-hydropower plants in Nepal: Sustainability from technical, economic and social perspectives. Paper presented at International Conference on the Developments in Renewable Energy Technology; 2018 Mar 29-31; Kathmandu, Nepal.

69. Butchers J, Williamson S, Booker J, Tran A, Gautam B, Bikram Karki P. A Study of Technical, Economic and Social Factors Affecting Micro-Hydropower Plants in Nepal. In: IEEE Global Humanitarian Technology Conference; 2018 Oct 18-21; San Jose, USA. Piscataway (US): IEEE; 2019.

70. Brown E, Leary J, Davies G, Batchelor S, Scott N. eCook: What behavioural challenges await this potentially transformative concept? Sustain Energy Tech Assess. 2017;22:106-15.

71. Williamson S. Modular and Scalable Low Head Pico-Hydro Generation for Off-Grid Networks [dissertation]. Bristol (UK): University of Bristol; 2014.

72. International Renewable Energy Agency. Renewable Energy Technologies Cost Analysis Series. Volume 1: Power Sector. Issue 3/5: Hydropower. Abu Dhabi (United Arab Emirates): IRENA; 2012. Available from: http://www.irena.org/documentdownloads/publications/re technologies cost analysis-hydropower.pdf. Accessed 2019 Sep 30.

73. Xiaohua W, Zhenmin F. Rural household energy consumption with the economic development in China: stages and characteristic indices. Energy Policy. 2001;29:1391-7.

74. Yadoo A, Gormally A, Cruickshank H. Low-carbon off-grid electrification for rural areas in the United Kingdom: Lessons from the developing world. Energy Policy. 2011;39:6400-7.

75. Maher P, Smith NPA, Williams AA. Assessment of pico hydro as an option for off-grid electrification in Kenya. Renew Energy. 2003;28:1357-69.

76. Kathmandu Alternative Power and Energy Group. Low Head Turbine and Electronic Load Controller. Available from: https://online.kapeg.com.np/ pico-hydro-system. Accessed 2019 Sep 30.

77. Nia Roodsari B, Nowicki EP, Freere P. The Distributed Electronic Load Controller: A New Concept for Voltage Regulation in Microhydro Systems with Transfer of Excess Power to Households. Energy Procedia. 2014;57:1465-74.

78. Williamson SJ. Concepts, Simulation and Testing for Pico Hydro Networks. In: Engineers Without Borders Research Conference; 2012 Mar 26; London, UK. London (UK): Engineers Without Borders; 2012. p. 55-60.

79. Paudel P, Wasti S. Peak Demand Management in Micro Hydro using Battery Bank. Hydro Nepal J Water Energy Environ. 2018;22:34-40.

80. Gyawali N, Ohsawa Y. Integrating Fuel Cell/Electrolyzer/Ultracapacitor System into a stand-alone micro hydro plant. IEEE Trans Energy Convers. 2010;25:1092-101.

81. Sturdivant RL, Yeh J, Stambaugh M, Zahnd A, Villareal N, Vetter CK. IoT enabled pico-hydro electric power with satellite back haul for remote 
himalayan villages. In: IEEE Topical Workshop on Internet of Space; 2018 Jan 14-17; Anaheim, USA. Piscataway (US): IEEE; 2018.

82. Leary J, While A, Howell R. Locally manufactured wind power technology for sustainable rural electrification. Energy Policy. 2012;43:173-83.

83. Kenfack J, Bossou OV, Voufo J, Djom S. Addressing the current remote area electrification problems with solar and microhydro systems in Central Africa. Renew Energy. 2014;67:10-9.

84. Hydro Empowerment Network Website. Available from: http://www.hpnet.org. Accessed 2019 Sep 30.

85. Pico Hydro Website. Available from: http://www.picohydro.org.uk. Accessed 2019 Sep 30.

86. Pico Turbine Pelton home-made powerhouse complete information waterwheel-video. Available from: https://www.youtube.com/watch? V=QosGYfa2kK4. Accessed 2019 Sep 30.

87. Mockmore CA, Merryfield F. The Banki Turbine. Corvallis (US): Oregon State College; 1949.

88. Kaunda CS, Kimambo CZ, Nielsen TK. Experimental study on a simplified crossflow turbine. Int J Energy Environ. 2014;5:155-82.

89. ENTEC CrossFlow Turbine TP100d. Available from: http://dbhsarl.eu/abc345/plans turbine crossflow entec.pdf. Accessed 2019 Sep 30.

90. Chiaradia T. Consolidation of Pico Component of MHPP. Available from: https://energypedia.info/images/d/d7/MHPP\%27s Pico Component 2007-08.p df. Accessed 2019 Sep 30.

91. Schumacher O, Austergard A. RHL/IAM Cross Flow Turbine. Available from: http://www.remotehydrolight.com/Introduction Cross flow turbine.pdf. Accessed 2019 Sep 30.

92. Portegijis J. The Firefly Microhydro System. Available from: https://www.microhydropower.net/mhp group/portegijs/firefly bm/ffbm in dex.html. Accessed 2019 Sep 30.

93. Ho-Yan B, Lubitz WD. Performance evaluation of cross-flow turbine for low head application. In: Proceedings of the World Renewable Energy Congress; 2011 May 8-13; Linköping, Sweden. Brighton (UK): World Renewable Energy Congress; 2011. p. 1394-9.

94. Alexander KV, Giddens EP, Fuller AM. Axial-flow turbines for low head microhydro systems. Renew Energy. 2009;34:35-47.

95. Butchers J. Mechanical development of the PT series of turbine in Nepal. PEEDA Energy Insight. 2017;4:11-5. Available from: http://peeda.net/downloads/energy-insight-volume-iv/. Accessed 2019 Sep 30.

96. Okamura T, Kurosaki R, Itani J, Takano M. Development and Introduction of a Pico-Hydro System in Southern Tanzania. Afr Stud Monogr. 2015;36:117-37.

97. Butchers J, Guerrini M, Kujawski M, Randall L. Design, optimisation and testing of a pico-hydro unit. Design Project Report. Bristol (UK): University of Bristol; 2013.

98. Swift KG, Booker JD. Manufacturing Process Selection. Oxford (UK): Butterworth-Heinemann; 2013. 
99. Mattson CA, Wood AE. Nine Principles for Design for the Developing World as Derived From the Engineering Literature. J Mech Design. 2014;136(12):121403.

How to cite this article:

Williamson SJ, Lubitz WD, Williams AA, Booker JD, Butchers JP. Challenges Facing the Implementation of Pico-Hydropower Technologies. J Sustain Res. 2020;2(1):e200003. https://doi.org/10.20900/jsr20200003 